\title{
Nonlinear Vibration of Ladle Crane due to a Moving Trolley
}

\author{
Yunsheng Xin $\mathbb{D},{ }^{1}$ Gening Xu $\mathbb{D},{ }^{1}$ Nina Su $\mathbb{D},{ }^{2}$ and Qing Dong ${ }^{1}$ \\ ${ }^{1}$ School of Mechanical Engineering, Taiyuan University of Science and Technology, Taiyuan 030024, China \\ ${ }^{2}$ College of Economics and Management, Taiyuan University of Technology, Taiyuan 030024, China \\ Correspondence should be addressed to Gening Xu; xugening@tyust.edu.cn
}

Received 19 September 2017; Revised 24 December 2017; Accepted 15 January 2018; Published 13 March 2018

Academic Editor: Xiao-Qiao He

Copyright (C) 2018 Yunsheng Xin et al. This is an open access article distributed under the Creative Commons Attribution License, which permits unrestricted use, distribution, and reproduction in any medium, provided the original work is properly cited.

\begin{abstract}
The structural vibration of the main beam of a crane causes fatigue damage and discomfort to the driver. The swing of the payload has an effect on positioning precision, especially for a ladle crane, and this directly affects production safety. To study the influence of system parameters on the vibration of a crane's main beam and the angle of the payload, a system consisting of the main beam, trolley, payload, and cabin was constructed. A rigid-flexible coupling dynamic model of a moving trolley with a hanging payload that moves on the flexible main beam with a concentrated cabin mass is established, and the direct integration method is used to solve the nonlinear differential equations of system vibration, which are obtained through Lagrange's equation. Then, the time domain responses of the flexible main beam, payload angle, and cabin vibration are obtained. The influences of the trolley running speed, quality of the payload, and quality and position of the cabin on the vibration of the main beam and payload angle are analyzed. The results indicate that the amplitude of the main beam is directly proportional to the quality of the trolley, payload, and cab; the position of the cabin is closer to the mid-span; the amplitude of the main beam is larger; the structural damping has some influence on the vibration of the main beam; and the swing angle of the payload is related to the maximum running speed of the trolley, acceleration time, and length of the wire rope. In order to reduce the vibration of the main beam and cabin, the connection stiffness of the cabin should be ensured during installation.
\end{abstract}

\section{Introduction}

The ladle crane is a type of overhead crane and carries out onerous work under extremely hostile environments. Its mechanism and structure can withstand the strong impact vibration of the trolley on the main beam. Many scholars have simplified the vibration system model to the moving load beam coupling system and have carried out a significant amount of research on the dynamic response of beams under moving mass.

Michaltsos et al. [1] dealt with the linear dynamic response of a simply supported uniform beam under a moving load of constant magnitude and velocity by including the effect of its mass. By using a series solution for the dynamic deflection in terms of normal modes, the individual and coupling effect of moving load mass, its velocity, and other parameters were fully assessed.

Şimşek [2] investigated the dynamic characteristics of the main beam when the moving mass was running on a simply supported beam, established the equilibrium equations of the system by using Lagrange's equations, and discussed the effects of shear deformation, various material distributions, velocity of the moving mass, inertia, Coriolis and the centripetal effects of moving mass on the dynamic displacements, and the stresses of the beam, in detail. Kiani et al. [3] investigated the maximum deflection and bending moment of the beams under various boundary conditions due to a moving mass by employing Hamilton's principle and using Euler-Bernoulli, Timoshenko, and third-order beam theories.

A comprehensive parametric investigation on the effects of moving mass weight and velocity on the dynamic behavior of a simply supported Euler-Bernoulli was carried out by Nikkhoo et al. [4], by employing the eigenfunction expansion method. They introduced a concept of critical velocity in terms of beam fundamental period, mid-span, and moving mass weight, in which the effect of convective accelerations in moving mass formulation was not negligible for masses moving with velocities greater than this critical one. 
Esmailzadeh and Ghorashi [5] analyzed the dynamic behavior of beams with simply supported boundary conditions, which carried either uniform partially distributed moving masses or forces, and evaluated the critical speeds of the moving load, by considering the maximum deflection for the midspan of the beam. Moreover, they verified that the length of the distributed moving mass affects the dynamic response considerably.

Lee [6] investigated the dynamic response of a Timoshenko beam, which is acted upon by a moving mass, by using the Lagrange approach and the assumed mode method. He verified the results of the model by comparing them with the results of an equivalent moving load for the mid-span deflection of a simply supported beam for a small number of moving mass weights and velocities as well as for different slenderness ratios of the base beam. Lou et al. [7] presented a finite element formulation of the Timoshenko beam subjected to a moving mass. Their results were in good agreement with those obtained by using the assumed mode method employed by Lee [6]. Many scholars have applied the model of mass moving on the beam to engineering practice. Lou et al. [8] and Cheng et al. [9] established a bridge-track-vehicle model in order to analyze the vibration of railway bridges under a moving train by taking into account the response of the track structure. The above-mentioned studies have only investigated the dynamic characteristics of the simply supported beam under a moving mass, or the quality of moving mass, running speed, acceleration, or other factors. There is no model of moving mass that accounts for swing quality.

The dynamic response of cranes has been studied by many scholars. Niu et al. [10] presented a general mathematical modeling approach for electric crane system dynamics during operation, which could be used to analyze the dynamic responses of electromagnetism, mechanism, and structure, during the operation of electric cranes. Wu et al. [11-14] established a mathematical model of the horizontal and vertical vibrations of a crane structure under the trolley running and lifting processes by using finite element theory and calculated the vibration response of the main beam. The correctness of the theoretical solution was verified by experimental verification, and the parameters were modified. Oguamanam et al. $[15,16]$ established an Euler-Bernoulli equation in order to investigate the vibration response of a fixed crane beam. Zrnić et al. [17] constructed multi-degree-of-freedom vibration models for crane structures in order to analyze the effects of wire rope length, damping ratio, and tilt angle of the sling load on structural vibration. Xin et al. [18] constructed a nine-degree-of-freedom mathematical model of a "human-crane-rail" system and an annoyance rate model for use in the optimization of the structural parameters of overhead traveling cranes and used the particle swarm optimization algorithm to optimize the structural design of overhead cranes. Some scholars predicted crane fatigue life by analyzing dynamics of vibration system $[19,20]$.

Although the dynamic characteristics of the main beam and the swing angle of the crane have been studied; these twoaspects have not been discussed simultaneously. The models reported in the literature contain only the main beam, trolley, and crane quality, without considering factors such as cabin quality, position, and structural damping of the main beam, which also affect the vibration of the main beam. The vibration time response of the cabin can be used to analyze the vibration of the human body during operation and thereby reduce the possibility of occupational disease. Therefore, this paper considers these factors in order to establish a dynamic model of the ladle crane vibration system. Based on the principle of energy conservation, the system vibration equation was established through Lagrange's equation. In combination with a direct integral method for solving the approximate solution of nonlinear vibration, the influence of factors such as the quality (trolley, payload, and cabin), trolley running speed, length of wire rope, position and connection stiffness of cabin on the vibration of the main beam, and the influence of the swing of payload was analyzed. In this study, the vibration acceleration and amplitude time domain responses of the cabin were obtained, which provide a theoretical reference for the optimization of crane design.

\section{Crane Vibration System Modeling}

2.1. Description of Vibration System. The ladle floating crane includes a frame, trolley movement organization, cabin, and suspension system, and the ladle crane system vibration dynamics model is established according to the size and structural characteristics, based on the following assumptions:

(1) The main beam is regarded as a flexible body, and only the vibration in the vertical direction is considered. If all the damping in the elastic body is viscous damping, the damping of the beam has very little influence on the vibration of the structure [21]; the damping ratio is usually $0.1 \%-0.7 \%$.

(2) The cabin is simplified as a lumped mass, and only the vertical vibration is considered. The connection between the cabin and the main beam is simplified as a spring and damping model with greater stiffness.

(3) According to the characteristics of the ladle crane, the rope is regarded as rigid without quality [22].

(4) The payload of the crane is reduced to a swinging mass, which is suspended in mass blocks by a nonmass rigid rope, which moves with the mass in the plane.

(5) The deflection of main beam is considered as linear, while the nonlinear effect of main beam deflection in the dynamic response analysis of the ladle crane is ignored.

The design method of the main beam consists of the allowable stress method and limit state method. The allowable stress method assumes that the deflection of the main beam is linear; however, the limit state method takes into consideration the nonlinear deflection of the main beam, while the fatigue analysis and the calculation of the crane beam structure's dynamic characteristics by these two methods have been reported in the literature $[23,24]$, where it was found that the results were basically the same with the exception 
of jib crane. Therefore, the nonlinear deflection of the beam had little effect on the dynamic response analysis of ladle cranes. In addition, after the completion of design and manufacturing, the beam of the bridge crane was formed on the precambering curve; therefore, the crane beam vibration amplitude was relatively small. Thus, this study adopted the mentioned hypothesis (5).

A schematic of the problem is depicted in Figure 1. The beam is simply supported and is assumed to be adequately modeled by using the Euler-Bernoulli beam theory. Only the bending stiffness was calculated, and the shear stiffness and torsion stiffness of the beam were not considered. The properties of the beam are Young's modulus $E$, volume density $\rho$, cross-sectional area $A$, length $l_{b}$, and second moment of area $I . m_{c}$ is the quality of the trolley, $m_{p}$ is the quality of the payload, $m_{b}$ is the quality of unit length for the main beam, $l_{p}$ is the length of the wire rope, $k_{d}$ is the connection stiffness between the cabin and the main beam, $c_{d}$ is the damping between the cabin and the main beam, $m_{d}$ is the quality of the cabin, $x_{d}$ is the mounting position coordinates of the cabin, $g$ is the gravitational acceleration, $V_{m}$ is the maximum running speed of the trolley, $\xi_{i}$ is the $i$ th modal damping ratio of the main beam structure, $x_{s}$ is the extreme left position of the trolley, $x_{e}$ is the extreme right position of the trolley, and $\theta_{x}$ is the swinging angle of the payload.

2.2. Dynamic Equations of the Vibration System. The trolley runs at the maximum speed $V_{m}$ on the main beam, and the elastic displacement curve of $x$ at moment $t$ in the $Z$ direction of the main beam can be expressed as follows:

$$
w(x, t)=\sum_{1}^{N} \phi_{i}(x) q_{i}(t)
$$

where $\phi_{i}(x)=\sin \left(i \pi x / l_{b}\right)$ is the $i$ th modal of the simply supported beam, and $q_{i}(t)$ and $N$ are the generalized coordinates and coordinate numbers of the elastic displacement of the main beam, respectively.

The coordinate vectors can be defined according to the simplified physical model shown in Figure 1. Therefore, the position vector of an elemental mass of beam $\overline{\mathbf{r}}_{\mathbf{b}}$, the position vector of carriage $\overline{\mathbf{r}}_{\mathbf{c}}$, the position vector of the payload $\overline{\mathbf{r}}_{\mathbf{p}}$, and the position vector of crane cabin $\overline{\mathbf{r}}_{\mathbf{d}}$ can be expressed as

$$
\begin{aligned}
& \overline{\mathbf{r}}_{\mathbf{b}}=x \cdot \mathbf{i}+w(x, t) \cdot \mathbf{k}, \\
& \overline{\mathbf{r}}_{\mathbf{c}}=x_{c} \cdot \mathbf{i}+w\left(x_{c}, t\right) \cdot \mathbf{k}, \\
& \overline{\mathbf{r}}_{\mathbf{p}}=\left(x_{c}+l_{p} \sin \theta_{x}\right) \cdot \mathbf{i}+\left(w\left(x_{c}, t\right)+l_{p} \cos \theta_{x}\right) \cdot \mathbf{k}, \\
& \overline{\mathbf{r}}_{\mathbf{d}}=x_{d} \cdot \mathbf{i}+\left(z_{d}-w\left(x_{d}, t\right)\right) \cdot \mathbf{k} .
\end{aligned}
$$

If the total kinetic energy of the system is $T$, the energy in the two main beams is $T_{b}$, the kinetic energy of the moving trolley is $T_{c}$, and the kinetic energy of payload is $T_{p}$, then the kinetic energy of each part of the system can be expressed as

$$
\begin{aligned}
T_{b} & =\frac{1}{4} m_{b} l_{b} \sum_{i=1}^{N} \dot{q}_{i}^{2}, \\
T_{c} & =\frac{1}{2} m_{c}\left\{\dot{x}_{c}{ }^{2}\right. \\
& \left.+\left[\dot{x}_{c} \sum_{i=1}^{N} \phi_{i}^{\prime}\left(x_{c}\right) q_{i}(t)+\sum_{i=1}^{N} \phi_{i}\left(x_{c}\right) \dot{q}_{i}\right]^{2}\right\}, \\
T_{p} & =\frac{1}{2} m_{p}\left\{\left[\dot{x}_{c} \sum_{i=1}^{N} \phi_{i}^{\prime}\left(x_{c}\right) q_{i}(t)+\sum_{i=1}^{N} \phi_{i}\left(x_{c}\right) \dot{q}_{i}\right]^{2}+\dot{x}_{c}{ }^{2}\right. \\
& +l_{p}{ }^{2} \dot{\theta}_{x}{ }^{2}+2 l_{p} \dot{x}_{c} \dot{\theta}_{x} \cos \theta_{x} \\
& \left.-2 l_{p} \dot{\theta}_{x} \sin \theta_{x}\left[\dot{x}_{c} \sum_{i=1}^{N} \phi_{i}^{\prime}\left(x_{c}\right) q_{i}(t)+\sum_{i=1}^{N} \phi_{i}\left(x_{c}\right) \dot{q}_{i}\right]\right\}, \\
T_{d} & =\frac{1}{2} m_{d}\left\{\left[\sum_{i=1}^{N} \phi_{i}\left(x_{d}\right) \dot{q}_{i}(t)\right]^{2}-2 \dot{z}_{d} \sum_{i=1}^{N} \phi_{i}\left(x_{d}\right) \dot{q}_{i}(t)\right. \\
& \left.+\dot{z}_{d}{ }^{2}\right\} .
\end{aligned}
$$

In the coupled system model, the system potential energy includes the elastic strain energy of beams $U_{b}$ and the elastic potential energy of the spring between the cab and beam $U_{d}$. In the process of movement, the work done by external forces (the gravity of cart, trolley, and payload) $W$ will also change the system potential.

The total potential energy for the system is

$$
U=U_{b}+U_{d}-W
$$

According to the principle of elastic mechanics, the main beam elastic strain energy is

$$
\begin{aligned}
U_{b} & =\frac{1}{2} E I_{y} \int_{0}^{l_{b}}\left[\frac{\partial^{2} w(x, t)}{\partial x^{2}}\right]^{2} d x \\
& =\frac{1}{2} E I_{y} \int_{0}^{l_{b}}\left[\sum_{i=1}^{N} \phi_{i}^{\prime \prime}(x) q_{i}(t)\right]^{2} d x \\
& =\frac{E I_{y} \pi^{4}}{4 l_{b}{ }^{3}} \cdot \sum_{i=1}^{N} i^{4} q_{i}^{2}(t) .
\end{aligned}
$$

The elastic potential energy of the spring between the cab and beam is

$$
U_{d}=\frac{1}{2} k_{d}\left[z_{d}-\sum_{i=1}^{N} \phi_{i}\left(x_{d}\right) q_{i}(t)\right]^{2} .
$$




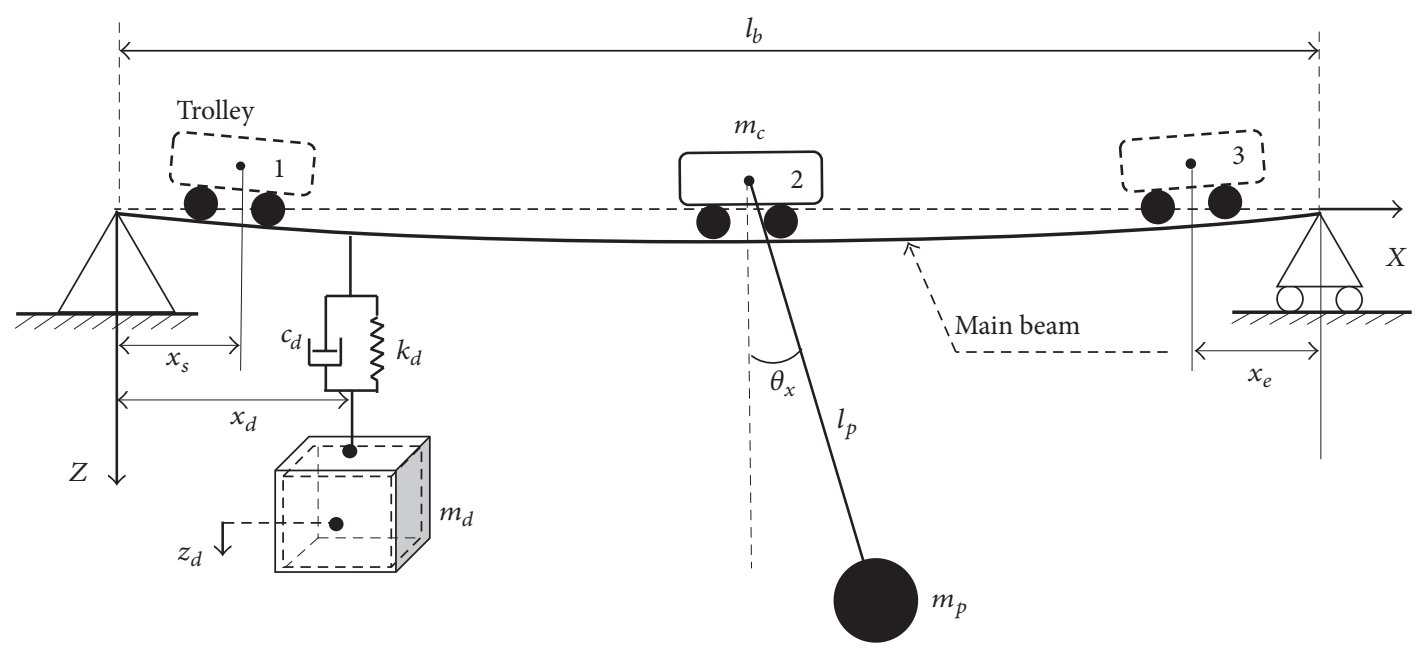

FIgURE 1: Physical model of crane vibration system.

The work done by external forces (the gravity of cart, trolley, and payload) is

$$
\begin{aligned}
W= & \left(m_{c}+m_{p}\right) g \cdot \sum_{i=1}^{N} \phi_{i}\left(x_{c}\right) q_{i}(t)+m_{p} g l_{p} \cos \theta_{x} \\
& +m_{d} g z_{d} .
\end{aligned}
$$

Equations (5), (6), and (7) are substituted into (4), and the potential energy $U$ in the system is expressed as

$$
\begin{aligned}
U= & \frac{E I_{y} \pi^{4}}{4 l_{b}{ }^{3}} \cdot \sum_{i=1}^{N} i^{4} q_{i}^{2}(t)-\left(m_{c}+m_{p}\right) g \\
& \cdot \sum_{i=1}^{N} \phi_{i}\left(x_{c}\right) q_{i}(t)-m_{p} g l_{p} \cos \theta_{x}-m_{d} g z_{d} \\
& +\frac{1}{2} k_{d}\left[z_{d}-\sum_{i=1}^{N} \phi_{i}\left(x_{d}\right) q_{i}(t)\right]^{2} .
\end{aligned}
$$

The dissipated energy $D$ in the system can be expressed as

$$
D=\frac{1}{2} \sum_{i=1}^{N} c_{i} \dot{q}_{i}^{2}(t)+\frac{1}{2} c_{d}\left(\dot{z}_{d}-\sum_{i=1}^{N} \phi_{i}\left(x_{d}\right) \dot{q}_{i}(t)\right)^{2} .
$$

The main beam damping $c_{i}$ in (9) can be obtained by (10) and (11). The $i$ th modal circular frequency of a simply supported beam with cross-section is

$$
\omega_{i}=\frac{i^{2} \pi^{2}}{l_{b}^{2}} \sqrt{\frac{E I}{m_{b}}} .
$$

Thus, the structural damping of the ith modal can be expressed as

$$
c_{i}=2 \xi_{i} m_{b} \omega_{i}
$$

where $\xi_{i}$ is the damping ratio of $i$ th modal.
Lagrange's equations of nonconservative systems are expressed as follows:

$$
\frac{d}{d t}\left(\frac{\partial T}{\partial \dot{y}_{i}}\right)-\frac{\partial T}{\partial y_{i}}+\frac{\partial U}{\partial y_{i}}+\frac{\partial D}{\partial \dot{y}_{i}}=F_{i} \quad(i=1,2, \ldots, n)
$$

where $T$ is the kinetic energy of the system, $U$ is the potential energy of the system, $D$ is the energy dissipation function of the system, $\partial D / \partial \dot{y}_{i}$ is the damping force caused by the energy dissipation function $D, F_{i}$ is the generalized excitation force of external action, $y_{i}$ is the generalized coordinate, and $\dot{y}_{i}$ is the generalized velocity.

According to (12), the differential equations for the motion of the system can be derived as follows:

$$
\begin{aligned}
& \frac{1}{2} m_{b} l_{b} \ddot{q}_{j}+\left(m_{c}+m_{p}\right) \cdot \phi_{j}\left(x_{c}\right) \sum_{i=1}^{N} \phi_{i}\left(x_{c}\right) \ddot{q}_{i} \\
& +m_{d} \phi_{j}\left(x_{d}\right) \sum_{i=1}^{N} \phi_{i}\left(x_{d}\right) \ddot{q}_{i}+2\left(m_{c}+m_{p}\right) \cdot \phi_{j}\left(x_{c}\right) \\
& \cdot \dot{x}_{c} \sum_{i=1}^{N} \phi_{i}^{\prime}\left(x_{c}\right) \dot{q}_{i}+2 \xi_{j} m_{b} l_{b} \omega_{j} \dot{q}_{j}+c_{d} \phi_{i}\left(x_{d}\right) \\
& \cdot \sum_{i=1}^{N} \phi_{i}\left(x_{d}\right) \dot{q}_{i}(t)+\left(m_{c}+m_{p}\right) \cdot \phi_{j}\left(x_{c}\right) \\
& \cdot\left(\ddot{x}_{c} \sum_{i=1}^{N} \phi_{i}^{\prime}\left(x_{c}\right) q_{i}(t)+\dot{x}_{c}{ }^{2} \sum_{i=1}^{N} \phi_{i}^{\prime \prime}\left(x_{c}\right) q_{i}(t)\right) \\
& +k_{d} \phi_{j}\left(x_{d}\right) \sum_{i=1}^{N} \phi_{i}\left(x_{d}\right) q_{i}(t)+\frac{E I_{y} \pi^{4} j^{4}}{2 l_{b}^{3}} q_{j}-\left(m_{c}\right.
\end{aligned}
$$




$$
\begin{aligned}
& \left.+m_{p}\right) g \phi_{j}\left(x_{c}\right)-k_{d} z_{d} \phi_{j}\left(x_{d}\right)-m_{p} \cdot l_{p} \phi_{j}\left(x_{c}\right) \\
& \cdot\left(\ddot{\theta}_{x} \sin \theta_{x}+\dot{\theta}_{x}^{2} \cos \theta_{x}\right)-m_{d} \phi_{j}\left(x_{d}\right) \ddot{z}_{d} \\
& -c_{d} \phi_{j}\left(x_{d}\right) \dot{z}_{d}=0, \\
& l_{p} \ddot{\theta}_{x}-\left[\left(\dot{x}_{c} \sum_{i=1}^{N} \phi_{i}^{\prime}\left(x_{c}\right) \dot{q}_{i}+\sum_{i=1}^{N} \phi_{i}\left(x_{c}\right) \ddot{q}_{i}\right)\right. \\
& +\ddot{x}_{c} \sum_{i=1}^{N} \phi_{i}^{\prime}\left(x_{c}\right) q_{i}(t) \\
& \left.+\dot{x}_{c}\left(\dot{x}_{c} \sum_{i=1}^{N} \phi_{i}^{\prime \prime}\left(x_{c}\right) q_{i}(t)+\sum_{i=1}^{N} \phi_{i}^{\prime}\left(x_{c}\right) \dot{q}_{i}(t)\right)\right] \sin \theta_{x} \\
& +g \sin \theta_{x}+\ddot{x}_{c} \cos \theta_{x}=0, \\
& +c_{d} \sum_{i=1}^{N} \phi_{i}\left(x_{d}\right) \dot{q}_{i}(t)=0 . \\
& m_{d}\left[\ddot{z}_{d}-\sum_{i=1}^{N} \phi_{i}\left(x_{d}\right) \ddot{q}_{i}(t)\right]+k_{d} z_{d} \\
& +\sum_{i=1}^{N} \phi_{i}\left(x_{d}\right) q_{i}(t)-m_{d} g+c_{d} \dot{z}_{d} \\
& +
\end{aligned}
$$

For a generic linear dynamic structural system, the equation of motion (see (13)) can be expressed in the following form:

$$
\mathbf{M} \ddot{\mathbf{q}}(t)+\mathbf{C} \dot{\mathbf{q}}(t)+\mathbf{K q}(t)=\mathbf{F}(t) .
$$

In (16), $\mathbf{M}, \mathbf{C}$, and $\mathbf{K}$ are mass, damping, and stiffness matrices of the system; $\ddot{\mathbf{q}}(t), \dot{\mathbf{q}}(t)$, and $\mathbf{q}(t)$ are the acceleration, velocity, and displacement vectors; and $\mathbf{F}(t)$ is a time-dependent loading vector. More details are included in Appendix.

2.3. Solving Method of Dynamic Response. The time domain response of the dynamic system can be obtained by using the direct integration method for a linear dynamic system with constant coefficients [18]. The Newmark method [25-27] is a typical implicit solution approach to structural dynamics problems and has the advantages of good convergence, precision, and stability. Not only is the method condition stable, but its stability condition is also easily satisfied.

The vibration equations of the system ((13)-(15)) constitute an $N+2$-dimensional two-order nonlinear time-varying differential equation system, which cannot obtain the exact solution directly. Therefore, a direct integration method and a matrix iteration method are used in this paper to approximate the vibration response of the system.
It is assumed that the acceleration varies linearly within the interval $(t, t+\Delta t)$, and that the Newmark scheme can be given in the following form:

$$
\begin{aligned}
\ddot{\mathbf{q}}_{t+\tau} & =\ddot{\mathbf{q}}_{t}+\frac{1}{\Delta t}\left(\ddot{\mathbf{q}}_{t+\Delta t}-\ddot{\mathbf{q}}_{t}\right) \tau \quad 0 \leq \tau \leq \Delta t, \\
\dot{\mathbf{q}}_{t+\Delta t} & =\dot{\mathbf{q}}_{t}+\left[(1-\gamma) \ddot{\mathbf{q}}_{t}+\gamma \ddot{\mathbf{q}}_{t+\Delta t}\right] \Delta t, \\
\mathbf{q}_{t+\Delta t} & =\mathbf{q}_{t}+\dot{\mathbf{q}}_{t} \Delta t+\left[\left(\frac{1}{2}-\beta\right) \ddot{\mathbf{q}}_{t}+\beta \ddot{\mathbf{q}}_{t+\Delta t}\right] \Delta t^{2},
\end{aligned}
$$

where $\gamma$ and $\beta$ are parameters determined by the stability and integration accuracy, respectively. The Newmark family of the method is unconditionally stable if

$$
\begin{aligned}
& \gamma \geq \frac{1}{2}, \\
& \beta \geq \frac{1}{4}\left(\frac{1}{2}+\gamma\right) .
\end{aligned}
$$

For any time-step, if (17) are substituted into (16), the system equation can be obtained as

$$
\widetilde{\mathbf{K}}_{t+\Delta t} \mathbf{q}_{t+\Delta t}=\widetilde{\mathbf{F}}_{t+\Delta t}
$$

In (16), the equivalent stiffness $\widetilde{\mathbf{K}}_{t+\Delta t}$ and equivalent load $\widetilde{\mathbf{F}}_{t+\Delta t}$ can be expressed in the following form:

$$
\begin{aligned}
\widetilde{\mathbf{K}}_{t+\Delta t}= & \mathbf{K}_{t+\Delta t}+a_{0} \mathbf{M}_{t+\Delta t}+a_{1} \mathbf{C}_{t+\Delta t}, \\
\widetilde{\mathbf{F}}_{t+\Delta t}= & \mathbf{F}_{t+\Delta t}+\mathbf{M}\left(a_{0} \mathbf{q}_{t}+a_{2} \dot{\mathbf{q}}_{t}+a_{3} \ddot{\mathbf{q}}_{t}\right) \\
& +\mathbf{C}\left(a_{1} \mathbf{q}_{t}+a_{4} \dot{\mathbf{q}}_{t}+a_{5} \ddot{\mathbf{q}}_{t}\right) .
\end{aligned}
$$

In (20), $a_{0}=1 / \beta \Delta t^{2} ; a_{1}=\gamma / \beta \Delta t ; a_{2}=1 / \beta \Delta t ; a_{3}=$ $1 / 2 \beta-1 ; a_{4}=\gamma / \beta-1 ; a_{5}=(\Delta t / 2)(\gamma / \beta-2)$. In this study, the parameters $\gamma=1 / 2$ and $\beta=1 / 4$ were chosen for all examples.

\section{Procedure of Solution}

The procedures for calculating the dynamic responses of the main beam and a swinging object undergoing a moving trolley $\left(m_{c}\right)$ are as follows:

(1) The initial values of the vibration responses of the main beam $\ddot{\mathbf{q}}_{0}, \dot{\mathbf{q}}_{0}$, and $\mathbf{q}_{0}$ are taken as 0 in the calculation process, similar to the initial values of the payload swing angles $\ddot{\theta}_{x 0}, \dot{\theta}_{x 0}$, and $\theta_{x 0}$, and the initial values of the cabin vibration response $\ddot{z}_{d 0}, \dot{z}_{d 0}$, and $z_{d 0}$. The dynamic response $\ddot{\mathbf{q}}_{\Delta \mathbf{t}}, \dot{\mathbf{q}}_{\Delta \mathbf{t}}$, and $\mathbf{q}_{\Delta \mathbf{t}}$ of (16) at moment $\Delta t$ is calculated by (17)-(20).

(2) The results obtained in step (1) are substituted into (14) and (15). The payload swing angle responses $\ddot{\theta}_{x \Delta t}$, $\dot{\theta}_{x \Delta t}$, and $\theta_{x \Delta t}$ are calculated according to (17) $-(20)$. The cabin vibration response $\ddot{z}_{d \Delta t}, \dot{z}_{d \Delta t}$, and $z_{d \Delta t}$ is the same.

(3) The results obtained by step (2) are substituted into step (1) in order to calculate the vibration response of the main beam at the next $\Delta t$ moment, and then step (2) is repeated in order to iteratively calculate steps (1) and (2), until a preset stop time is reached. 
TABLE 1: Initial values of system parameters.

\begin{tabular}{lc}
\hline Parameter & Value \\
\hline$m_{c}$ & $20000 \mathrm{~kg}$ \\
$m_{p}$ & $20000 \mathrm{~kg}$ \\
$\rho$ & $7820 \mathrm{~kg} / \mathrm{m}^{3}$ \\
$E$ & $2.06 \times 10^{11} \mathrm{~N} / \mathrm{m}^{2}$ \\
$I$ & $0.0093 \mathrm{~m}^{4}$ \\
$x_{s}$ & $2.25 \mathrm{~m}$ \\
$l_{b}$ & $28.5 \mathrm{~m}$ \\
$l_{p}$ & $5.7 \mathrm{~m}$ \\
$\xi_{i}$ & 0.001 \\
$g$ & $9.81 \mathrm{~N} / \mathrm{kg}$ \\
$A$ & $0.128 \mathrm{~m}$ \\
$x_{e}$ & $2.25 \mathrm{~m}$ \\
$k_{d}$ & $10^{8} \mathrm{~N} / \mathrm{m}$ \\
$c_{d}$ & $10^{5} \mathrm{~N} / \mathrm{m} \cdot \mathrm{s}$ \\
$x_{d}$ & $5 \mathrm{~m}$ \\
$m_{d}$ & $2000 \mathrm{~kg}$ \\
$V_{\max }$ & $72 \mathrm{~m} / \mathrm{min}$ \\
$\theta_{x}$ & $0 \mathrm{rad}$ \\
\hline
\end{tabular}

(4) Determine whether the calculation results $\ddot{\mathbf{q}}(t), \ddot{\theta}_{x}(t)$, and $\ddot{z}_{d}(t)$ are convergent. If not, return to step (2) for further analysis and calculation.

The Newmark method used in this study should be unconditionally convergent, when calculating the numerical solution of system vibration [25,26]. Therefore, it is necessary to determine the convergence of the calculation results through the time domain response of the vibration of the main beam. In engineering practice, when the trolley is running close to the mid-span, the vertical central displacement of the main beam is larger, and when the mid-span distance is greater, the vertical central displacement of the main beam is smaller. If the calculation results align with this situation, the result of the calculation converges $[5,14]$.

\section{Numerical Results and Discussion}

This study considered a 100/40 $\mathrm{t}$ and $28.5 \mathrm{~m}$ ladle crane made by Taiyuan Heavy Industry Limited Company as an example. During the service period of the crane, the rails were defective due to the influence of the foundation's differential settlement. In addition, there were vibrations of the human body and damage of equipment. The initial parameters of the crane vibration system are shown in Table 1.

\subsection{System Model Validation}

4.1.1. Beam Subjected to Moving Mass. To further confirm the reliability of the presented formulae and the developed computer programs, a pinned-pinned beam subjected to a moving mass $m=70 \mathrm{~kg}$ and constant speed of $V_{m x}=$ $3.34 \mathrm{~m} / \mathrm{s}$ was also investigated. The length of the beam was $L_{b}=10 \mathrm{~m}$ and the cross-sectional area was $A=9.0024 \times$ $10^{-4} \mathrm{~m}^{2}$, and second moment of area was $I=1.04 \times 10^{-6} \mathrm{~m}^{4}$.

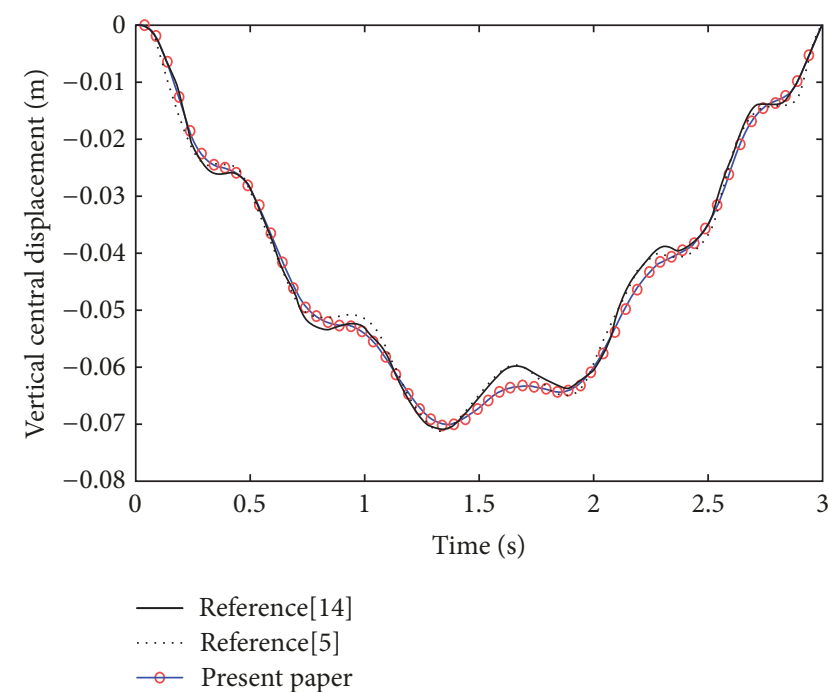

Figure 2: Calculation results of central displacement position deflection compared to references $[5,14]$.

The mass density was $\rho=7820 \mathrm{~kg} / \mathrm{m}^{3}$ and Young's modulus was $E=2.068 \times 10^{11} \mathrm{~N} / \mathrm{m}^{2}$. The above information of the beam was almost the same as references $[5,14]$.

Figure 2 shows the time histories for the vertical central displacements of the pinned-pinned beam. In [14], the influence of the moving mass on the midpoint shape of the simply supported beam was solved by using finite element theory. Additionally, in reference [5], the dynamic response of the middle point of the main beam was solved under a modal assumption. However, in this study, the time domain response of the midpoint vibration of the main beam was solved by combining the modal hypothesis with the energy conservation of the system. As can be seen from Figure 2, three calculation results were consistent with the underlying trend. Since the differences between the last three curves were small, the formulations and computer programs developed in this study should be available for calculating the dynamic responses of a structure due to a moving load.

4.1.2. Swing Angle Verification. The payload swing is affected by the carriage traverse acceleration and the length of the wire rope. The reliability of the presented formulae and the developed computer programs were further confirmed with regard to the swing angle. A pinned-pinned beam was subjected to a moving mass of $m_{c}=97.9 \mathrm{~kg}$ and a payload quality of $m_{p}=97.9 \mathrm{~kg}$. The beam had a length of $l_{b}=6 \mathrm{~m}$ crosssectional area of $A=2.04 \times 10^{-2} \mathrm{~m}^{2}$, and second moment of area $I=2.13 \times 10^{-7} \mathrm{~m}^{4}$. The mass density was $\rho=$ $8000 \mathrm{~kg} / \mathrm{m}^{3}$ and Young's modulus was $E=2.11 \times 10^{11} \mathrm{~N} / \mathrm{m}^{2}$. In practice, the carriage starts with an initial velocity of zero and accelerates to a particular speed, which could be held constant for some time before decelerating to rest. In all cases, the terminal times of the intervals were $t_{1}=15 \mathrm{~s}, t_{2}=45 \mathrm{~s}$, and $t_{3}=60 \mathrm{~s}$, the speed during the constant speed phase was $V=0.1333 \mathrm{~m} / \mathrm{s}$, and the deceleration phase occurred over the 


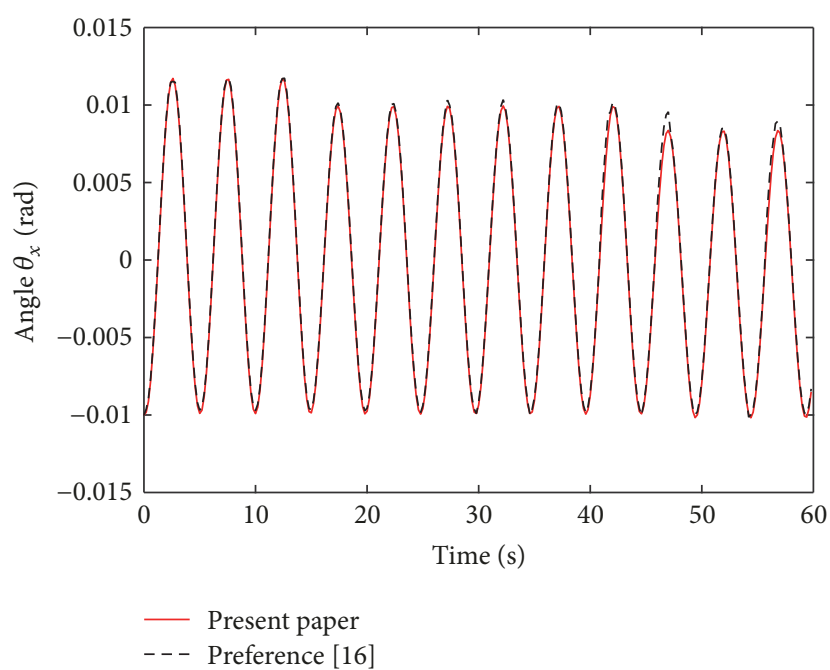

FIgURE 3: Consistency comparison of calculated results to [16].

last meter of the motion. The initial displacements for each swing angle were $\theta_{x}(0)=-0.01(\mathrm{rad})$.

The quality of the cabin, the connection stiffness, and damping were all set to zero. By ignoring the structural damping effect, the factors were considered to be consistent with those reported in [16]. From Figure 3, it can be seen that the results of this study are similar to those reported in [16], which proves the validity of the calculation principle and procedure.

\subsection{Dynamic Response of Crane Main Beam and Payload} Swing Angles. The main beam on the side of the cabin was selected as the object of analysis. Therefore, the effect of trolley on the main beam was half of the trolley's quality, and only half of the wire rope was applied to the main beam. According to the system vibration equation model, the factors affecting the dynamic response of the crane's main beam are related not only to the cross-section properties and dimension parameters of the main beam, but also to the quality of the trolley, running speed, and quality and position of the cabin. This study uses these aspects to carry out an analysis on the vibration of the main beam and payload swing angle response.

4.2.1. The Effect of Trolley Quality and Running Speed on Dynamic Response. In comparison to other cranes, the ladle crane lifting steel ladle is a high-risk item. Running too fast may directly lead to an excessively large swing angle, which greatly reduces the safety of the production process. Therefore, the trolley of the ladle crane is run slower than that of other cranes by up to approximately $80 / \mathrm{min}$. In fact, for the trolley running speed patterns shown in Figure 4, the time for trolley acceleration and deceleration was set to $5 \mathrm{~s}$. The track of the trolley runs from the limit position on one side to the limit position on the other side. The maximum running speed of the trolley was $V_{m}^{3}=1.2 \mathrm{~m} / \mathrm{s}$. This ensured the safety of

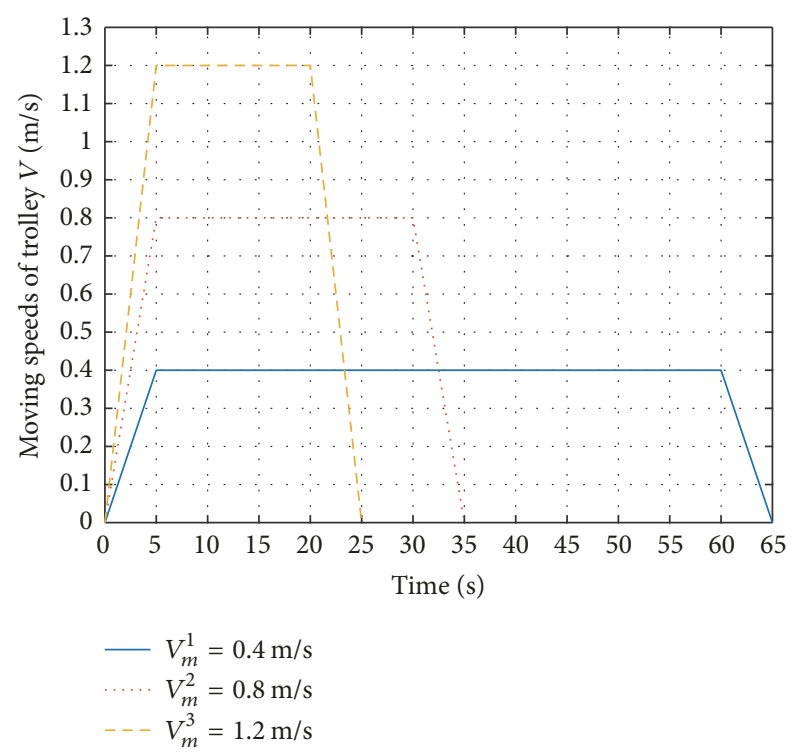

FIGURE 4: Three speed patterns for the moving system-trolley.

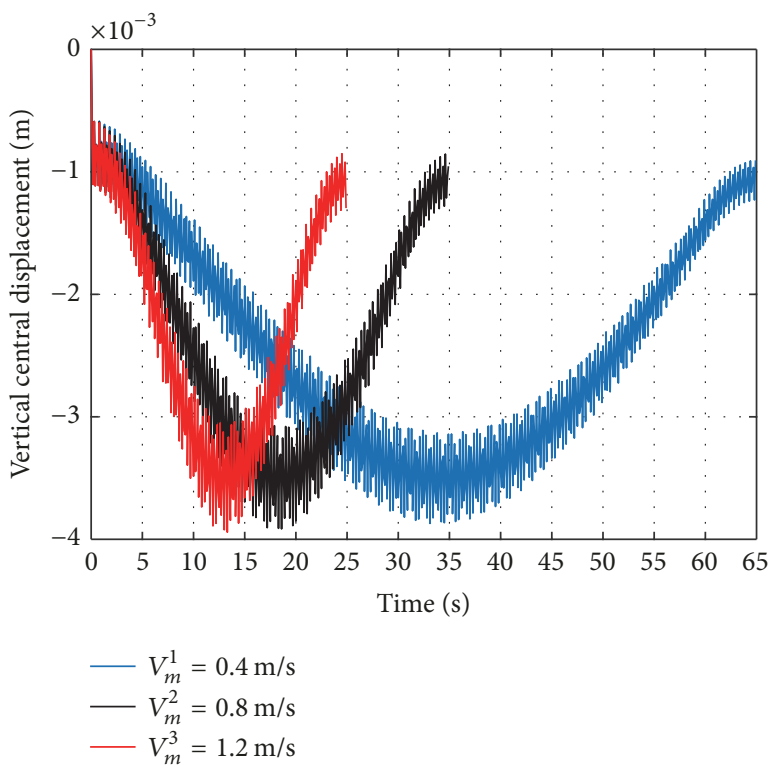

FIGURE 5: Influence of trolley speed on center deflection of main beam.

the trolley during the operation. The responses in Figure 4 are based on the three operating patterns of the trolley.

Figure 5 shows the vertical central displacement response of the crane's main beam vibration for the three speed patterns of the trolley. When the trolley was running near the center of the main beam, the amplitude of the central displacement was the largest. The maximum running speeds of the trolley were $0.4 \mathrm{~m} / \mathrm{s}, 0.8 \mathrm{~m} / \mathrm{s}$, and $1.2 \mathrm{~m} / \mathrm{s}$, while the maximum vertical central displacements were $3.7 \mathrm{~mm}, 3.8 \mathrm{~mm}$, and $3.9 \mathrm{~mm}$, respectively. Therefore, the faster the maximum speed of trolley in this range, the greater the vertical central displacement. However, the change was not obvious. 


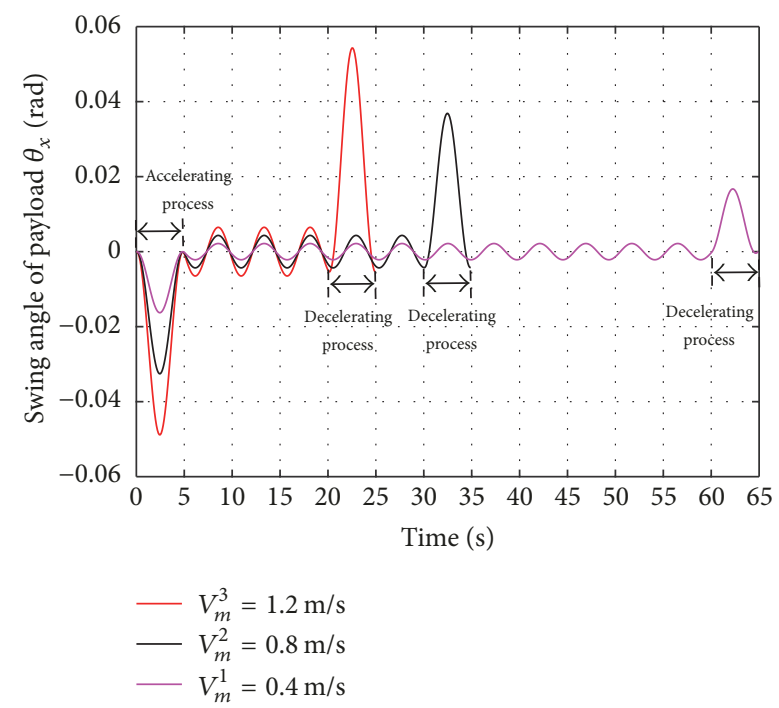

FIGURE 6: Influence of trolley running speed on swing angle of payload.

Figure 6 shows the time domain response of the payload swing angle at different running speeds of the trolley. In the pattern of speed $V_{m}^{3}$, the swing angle first increased and then reduced in the $0-5 \mathrm{~s}$ acceleration phase. In the 5-20 s uniform running phase, the payload presented a reciprocating periodic swing. The swing period of the payload was $T=2 \pi \sqrt{l_{p} / g}$. By substituting the initial parameters, the period was calculated as $4.7894 \mathrm{~s}$, which is the same as that of the uniform running phase, thus proving that the results are correct. In 20-25 s, the deceleration phase, payload, and swing angle first increased and then decreased. This is due to the slowdown in the uniform motion effect to increase the amplitude of the payload. The swing amplitude of the acceleration phase was $2.75^{\circ}$, while the amplitude of the deceleration phase was $3.15^{\circ}$. The swing amplitude of the deceleration phase was slightly larger than that of the acceleration phase. This is because the payload still had a swing speed at the end of the uniform motion, and the direction of the velocity coincided with the direction of the deceleration run.

When the maximum running speed of the trolley was $0.4 \mathrm{~m} / \mathrm{s}, 0.8 \mathrm{~m} / \mathrm{s}$, and $1.2 \mathrm{~m} / \mathrm{s}$, the maximum swing angle in the acceleration phase was $0.17 \mathrm{rad}, 0.32 \mathrm{rad}$, and $0.49 \mathrm{rad}$, respectively, and the deceleration phase was $0.18 \mathrm{rad}, 0.38 \mathrm{rad}$, and $0.55 \mathrm{rad}$, respectively, as shown in Figure 6 . Since the maximum speed of the trolley was faster, the amplitude of the payload increased significantly. This is because at the same acceleration or deceleration time $(5 \mathrm{~s})$, the faster the acceleration, the greater the swing angle of the payload. By changing the quality of the trolley and payload or the cabin stiffness value, the calculated results remain essentially unchanged. Thus, the swing angle of payload is related to the speed and acceleration of the trolley, regardless of the trolley quality and payload, or the cabin stiffness value.

It can be seen from Figure 7 that the trend of central displacement of the main beam for different trolley qualities

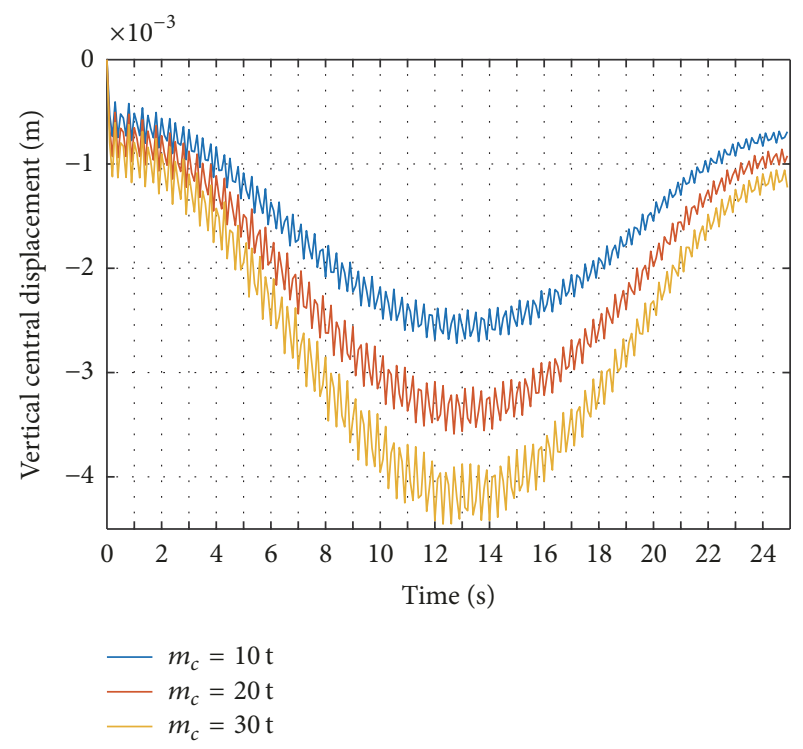

FIGURE 7: Influence of trolley quality on central displacement of main beam.

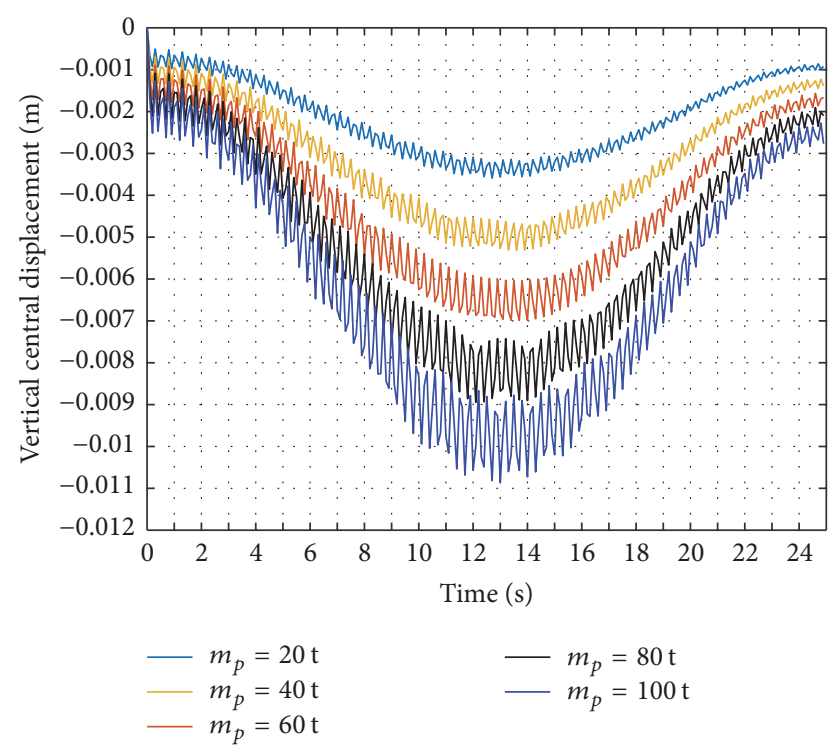

FIGURE 8: Influence of payload quality on central displacement of main beam.

remains essentially unchanged. For trolley qualities of $10 \mathrm{t}$, $20 \mathrm{t}$, and $30 \mathrm{t}$, the maximum deflection was $2.7 \mathrm{~mm}, 3.6 \mathrm{~mm}$, and $4.4 \mathrm{~mm}$, respectively. With the increase in trolley quality, there was a corresponding increase in vertical central displacement.

\subsubsection{Influence of Payload Quality and Rope Length on Crane} Dynamic Response. As shown in Figure 8, with the increase in payload quality, the deflection of central displacement of main beam increases, and the nonlinearity of vibration becomes more and more obvious.

As can be seen from Figure 9, the results are in agreement with the different lengths of the wire rope. Therefore, the 


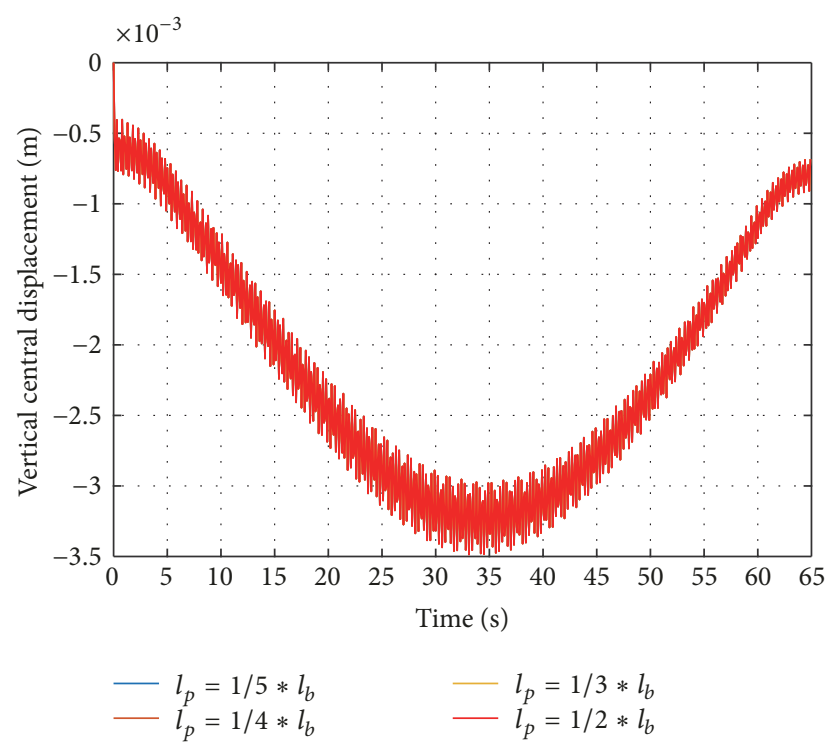

FIGURE 9: Influence of length of wire rope on central displacement of main beam.

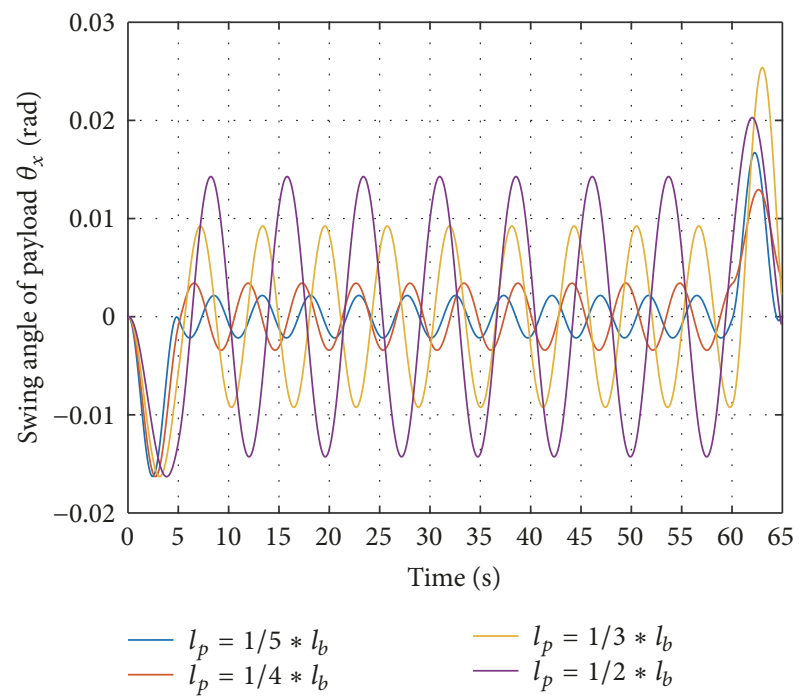

Figure 10: Influence of wire rope length on swing angle.

length of the wire rope has little effect on the vibration of central displacement of the main beam. This is because the swing angle was very small, as was the change in energy of the wire rope length. The quality of the payload in the swing model plays a major role in the deformation of the main beam.

According to the swing period of the payload $T=$ $2 \pi \sqrt{l_{p} / g}$, the length of the wire rope affects the swing period of the payload. As can be seen in Figure 10, the payload swing angles of different rope lengths differ slightly in the $0-5 \mathrm{~s}$ acceleration phase; the amplitude of swing angle increases with the rope length in the 5-60 s uniform running phase; there is no necessary linear relationship between the swing amplitude and rope length in the $60-65 \mathrm{~s}$ deceleration phase.

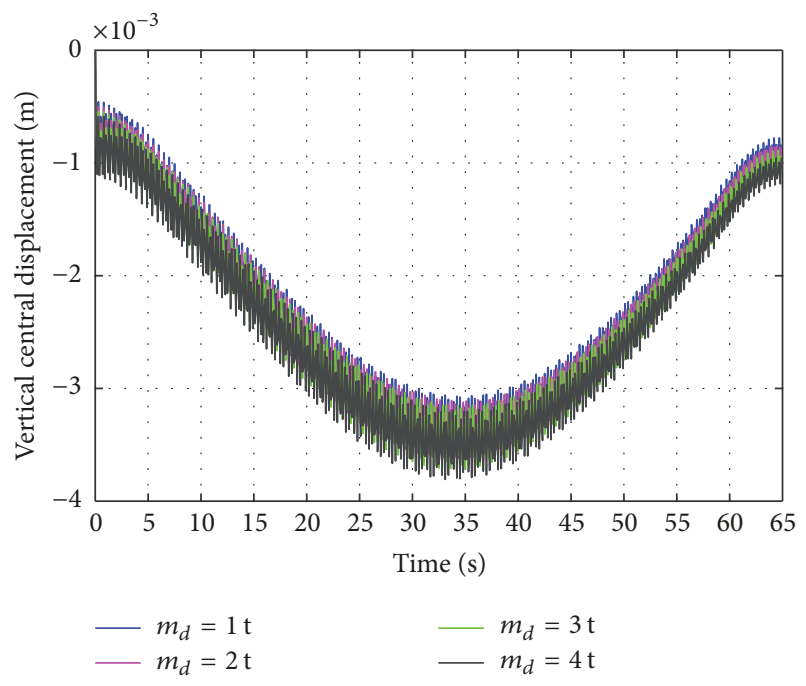

FIGURE 11: Influence of cabin quality on central displacement of main beam.

The main reason for these phenomena is that rope length determines the swing period of the payload. In this example project, the acceleration and deceleration times of the trolley were designed as $5 \mathrm{~s}$, while the swing period of the payload was $4.79 \mathrm{~s}, 5.35,6.18 \mathrm{~s}$, and $7.57 \mathrm{~s}$. In the acceleration phase, when the incentive effect of the trolley on the payload disappeared, the initial position of the payload swing was very different. Therefore, there was a big difference between the swing amplitude in the uniform running phase. Similarly, due to the differences in the starting phase angle and the period in the deceleration phase, there was no linear change in the swing amplitude. In the design of the crane, it is necessary to investigate the swing period of the payload and the acceleration time of the trolley, so that the payload of the swing angle can be fundamentally reduced. The angle of the payload can be reduced by controlling the length of the wire rope.

\subsubsection{Influence of Associated Parameters of Cabin on Dynamic} Response of Crane. In this model, the cabin is reduced to a lumped mass. The quality of the cabin has some influence on the deformation of the main beam (see Figure 11). The amplitude of the vertical direction of the main beam increases as the quality of the cabin becomes heavier. However, the quality of the cabin was very light, in comparison to the quality of the main beam and trolley; therefore, the impact on the vibration of the main beam was smaller.

The cabin position is usually designed to be the cross end of the main beam of the crane, which reduces the effect of the vertical direction of the main beam. This helps to improve the comfort of the driver during operation and reduces the possibility of occupational diseases. The position of the cabin can be changed within a small range in the design process. The closer the cabin is to the mid-span, the larger the amplitude in the vertical direction, and the higher the sensitivity (see Figure 12). 


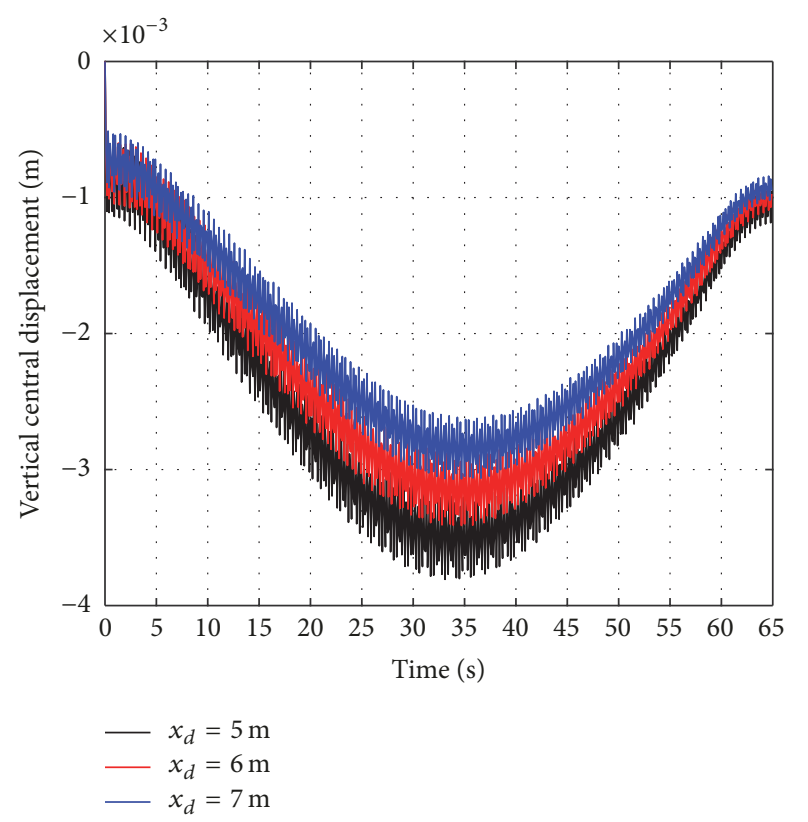

FIGURE 12: Influence of cabin position on central displacement of main beam.

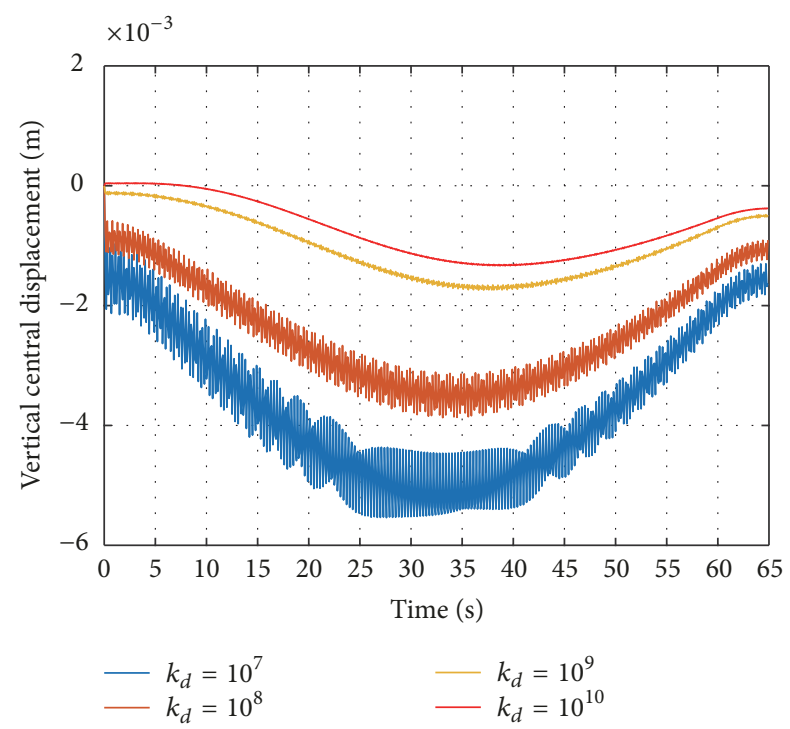

FIGURE 13: Influence of connection stiffness on central displacement of main beam.

The influence of the connection stiffness on the central displacement of the main beam is shown in Figure 13. When the values of connection stiffness are $k_{d}=10^{7}$ and $k_{d}=10^{8}$, the nonlinearity of the mid-span vibration is not obvious; however, when the values of connection stiffness are $k_{d}=10^{9}$ and $k_{d}=10^{10}$, it is obvious that the amplitude is inversely proportional to the connection stiffness. When the connection stiffness is small, the vibration of the cabin is strong and has a great influence on the vibration of the main beam. Therefore, in the installation of the cabin, it should be kept

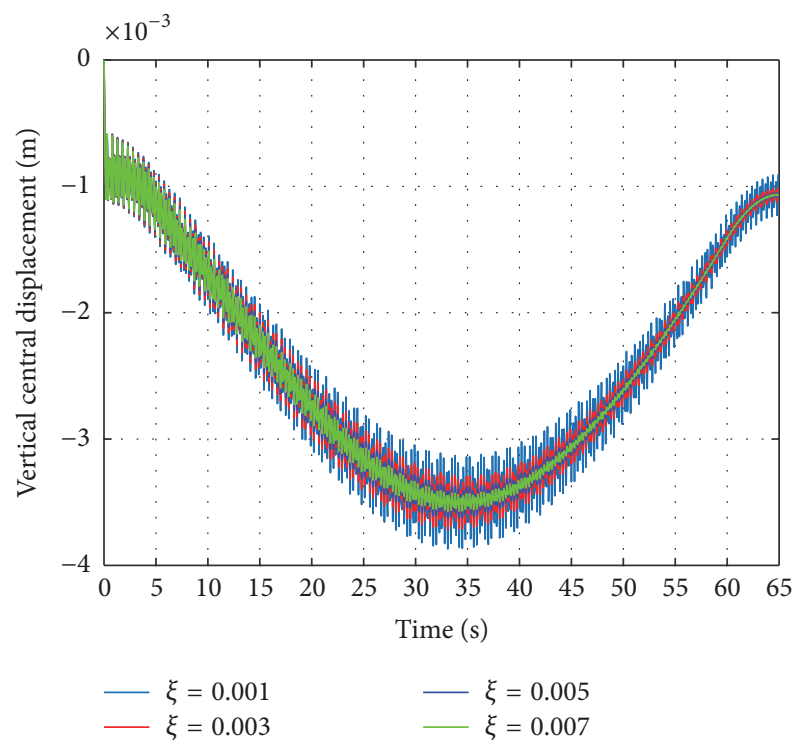

FIGURE 14: Influence of structural damping on the central displacement of main beam.

close to the main beam, and the space for activity should be avoided.

4.2.4. Structural Damping of Simply Supported Beam. As has been reported in the literature, although the structural damping of the main beam is small, it has a subtle effect on the vibration of the crane's main beam system. These subtle effects may cause problems in the crane design process. As can be seen in Figure 14, when $\xi=0.001$, the vibration is nonlinear and the maximum amplitude is $3.8 \mathrm{~mm}$. The vibration of the trolley, when it runs to the end of the main beam, is still nonlinear. When $\xi=0.007$, the fluctuation of the vibration is reduced and the maximum amplitude is $3.55 \mathrm{~mm}$. The damping dissipates some energy, which reduces the vibration energy.

4.3. Dynamic Response Analysis of Cabin. The vibration of the cabin can reflect the comfort of the driver during operation. In the model, the connection stiffness of the cabin is a direct cause of vibration. Figures 15-17 show the vibration response under different values of connection stiffness. As can be seen from Figure 15, the stronger the connection stiffness of the cabin, the smaller the vibration amplitude of the cabin. When $k_{d}=10^{10}$, the vibration amplitude of the cabin is basically zero. In addition, when $k_{d}=10^{7}$, the amplitude of the vibration of the cabin fluctuates violently; the nonlinearity is obvious and the maximum amplitude is $7.7 \mathrm{~mm}$. When the values of connection stiffness are $k_{d}=10^{9}$ and $k_{d}=10^{10}$, the relative displacement of the cabin and the main beam is basically zero, and when $k_{d}=10^{7}$, it is $5.2 \mathrm{~mm}$ (see Figure 16). As can be seen in Figure 17, the stronger the cabin connection stiffness, the slower the acceleration of the cabin. In summary, in order to reduce the vibration intensity of the cabin and to improve the operating comfort of the driver, the cabin must be well fixed at the end of the main beam. 


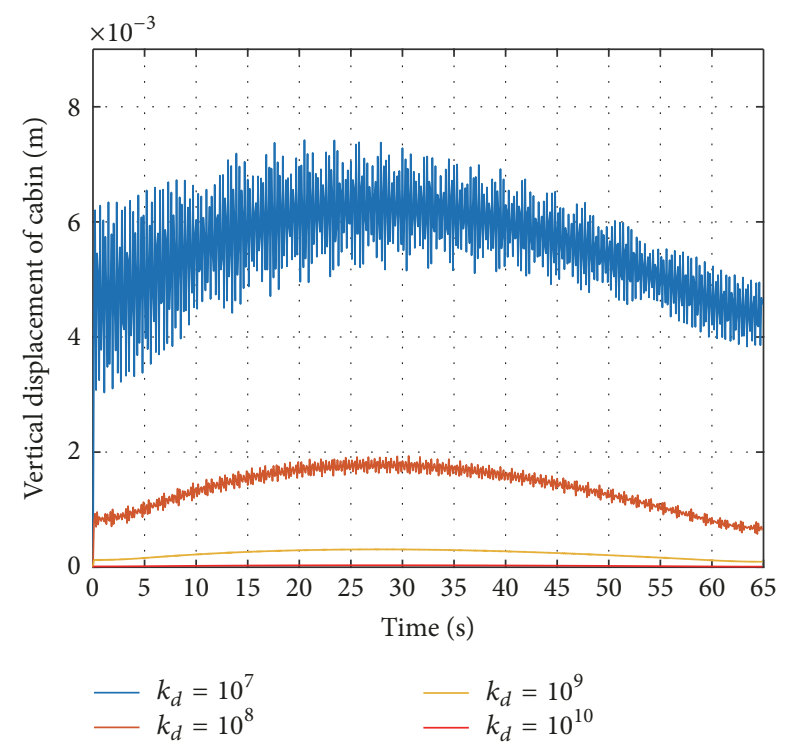

FIGURE 15: Vertical displacement of cabin under different values of connection stiffness.

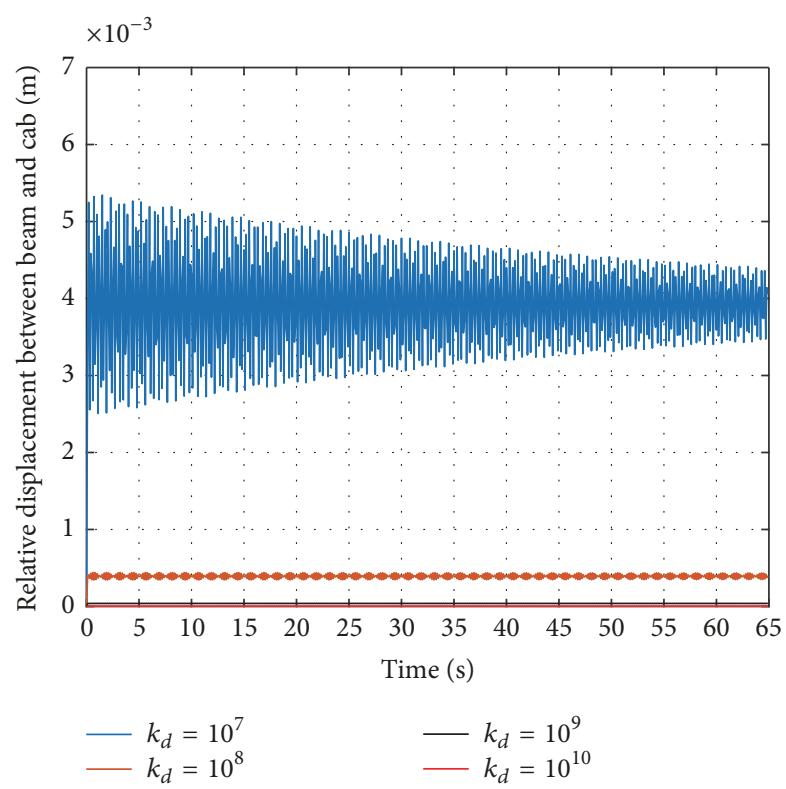

FIGURE 16: Relative displacement between beam and cabin under different values of connection stiffness.

4.4. Influence of Nonlinear Analysis on the Main Beam and Cabin. Nonlinearity is a common phenomenon in nature, and linearity is a special case of nonlinearity. The nonlinear theory for interpreting the physical phenomena of crane system vibration has universal significance. The nonlinear vibration equations of the rigid-flexible coupling vibration system of cranes obtained in Section 2 include the nonlinear elements of the system. The motivation force $\mathbf{F}(t)$ in the Appendix is related not only to the mass of trolley and hoisting but also to the swing angle and vibration of the cabin, which indicates nonlinear characteristics that are more complex. In this section, the dynamic response effect of the crane

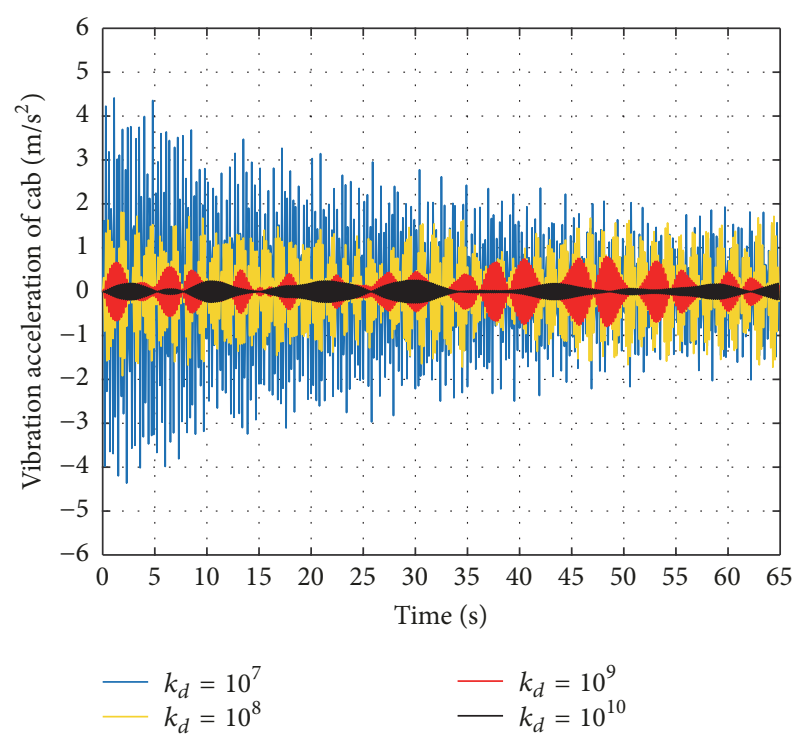

FIGURE 17: Vibration acceleration of cabin under different values of connection stiffness.

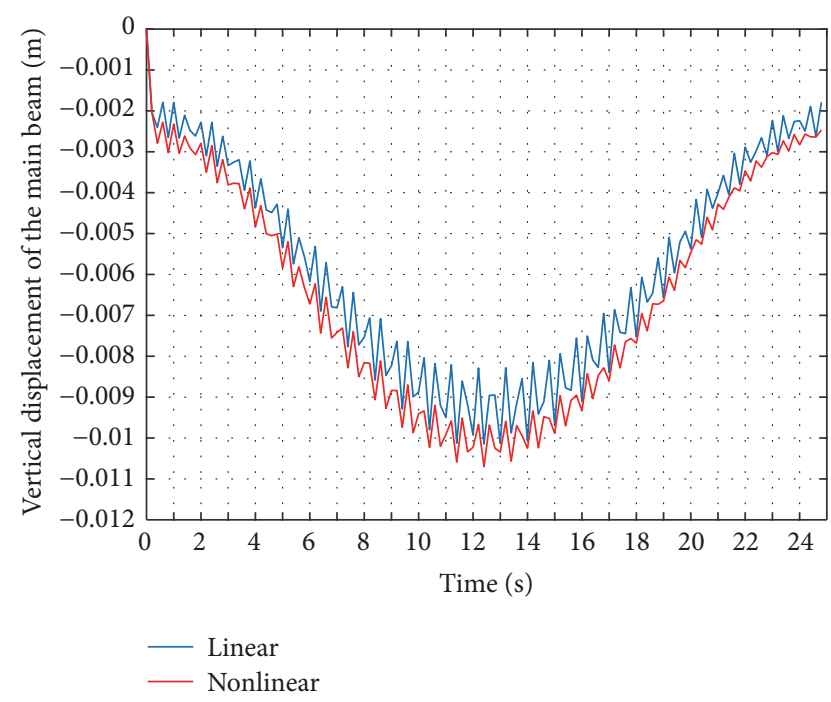

FIGURE 18: Influence of nonlinear analysis on the main beam.

beam and cabin in a linear system are calculated by ignoring the nonlinearities in the equation. By comparing the calculation results of the linear system and nonlinear system, the influence of nonlinear factors on the vibration of main beam and cabin can be seen.

For analyzing the influence of nonlinear factors on the vibration of a crane system, we selected the following parameters: trolley mass $m_{c}=2000 \mathrm{~kg}$, payload quality $m_{p}=$ $2000 \mathrm{~kg}$, maximum running speed of trolley $V_{m}^{3}=1.2 \mathrm{~m} / \mathrm{s}$, and connection stiffness of cabin $k_{d}=10^{7} \mathrm{~N} / \mathrm{m}$.

The vibration time domain responses of the main beam and cabin, in both linear and nonlinear systems, are shown in Figures 18 and 19, respectively. As can be seen from the 


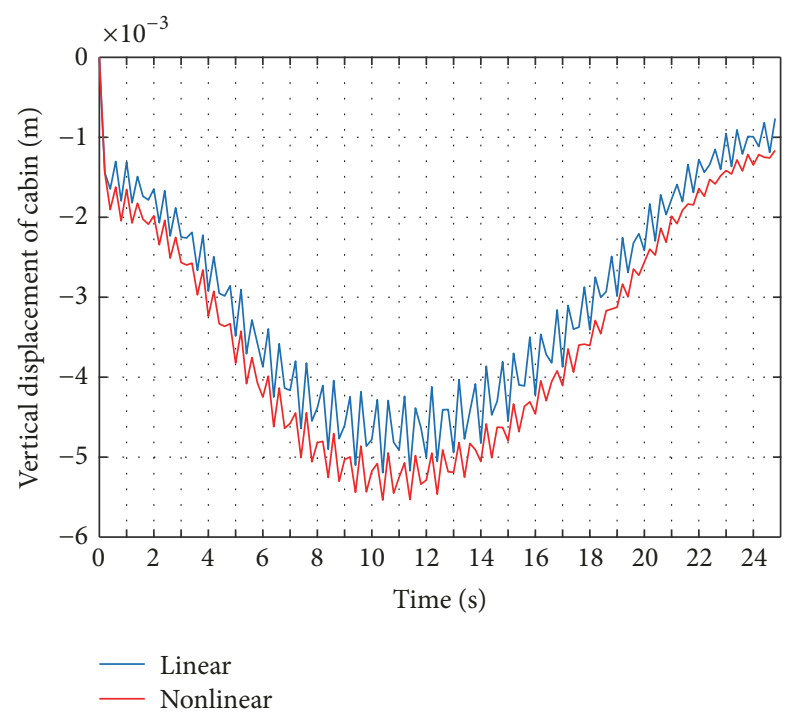

Figure 19: Influence of nonlinear analysis on the cabin.

figures, the curve of displacement response of the main beam and cabin for a nonlinear system is below that for a linear system. Therefore, nonlinear factors affect the vibration of the main beam and cabin. The maximum amplitudes of vibration of the main beam and cabin in a linear system are $10.1 \mathrm{~mm}$ and $5.1 \mathrm{~mm}$, respectively, whereas the maximum amplitudes of vibration of the main beam and cabin in a nonlinear system are $10.7 \mathrm{~mm}$ and $5.5 \mathrm{~mm}$, respectively. In a nonlinear system, the vibration responses of the main beam and cabin are increased by $5.9 \%$ and $7.8 \%$, respectively. Ladle cranes are mainly used for lifting molten steel. When ladle cranes are fully loaded, the deformation of the main beam will reach its maximum. These effects of nonlinear factors may directly cause accidents and result in significant loss of personnel and property. Therefore, in the analysis and calculation process, it is very important to consider the nonlinear factors.

\section{Conclusion}

Based on the principle of system dynamics, a system vibration model of the flexible main beam, cabin, trolley, and payload is established, which can provide a theoretical basis for crane design. The vibration function of the main beam is obtained by the mode superposition method, and the system vibration equation is established by Lagrange's equation. The dynamic responses of the main beam and payload are obtained from the approximate solution of nonlinear system vibration.

The vertical amplitude of the main beam is directly proportional to the quality of the trolley and payload. In the acceleration time of $5 \mathrm{~s}$, when the maximum running speed of the trolley is $0.4 \mathrm{~m} / \mathrm{s}, 0.8 \mathrm{~m} / \mathrm{s}$, and $1.2 \mathrm{~m} / \mathrm{s}$, the maximum amplitude of the mid-span of the main beam is not significant. The quality of the cabin has little influence on the vibration of the main beam; however, the influence of the position is obvious. The closer the cabin is to the main beam, the larger the amplitude is. At the same time, when the connection stiffness of the cabin is weak, the amplitude fluctuation of the main beam is high, and the nonlinearity of the vibration is more obvious. In contrast, structural damping can only change the vibration amplitude of the main beam and the speed of energy attenuation within a certain range, which has little effect on the vibration of the main beam.

For the same acceleration and deceleration times, the swinging angle of the payload increases with the speed of the trolley. Since the length of the wire rope affects the swing period of the payload, the influence of acceleration and deceleration times on the payload swing angle is more complex and requires further research. As the next step, research on antiswing control, based on the flexibility of the wire rope, can be considered.

\section{Appendix}

$$
\begin{gathered}
\mathbf{M}=\left[\begin{array}{cccc}
1+P_{M} \varphi_{11 c}+D_{M} \varphi_{11 d} & P_{M} \varphi_{12 c}+D_{M} \varphi_{12 d} & \cdots & P_{M} \varphi_{1 N c}+D_{M} \varphi_{1 N d} \\
P_{M} \varphi_{21 c}+D_{M} \varphi_{21 d} & 1+P_{M} \varphi_{22 c}+D_{M} \varphi_{22 d} & \cdots & P_{M} \varphi_{2 N c}+D_{M} \varphi_{2 N d} \\
\vdots & \vdots & \ddots & \vdots \\
P_{M} \varphi_{N N c}+D_{M} \varphi_{N N d} & P_{M} \varphi_{N 2 c}+D_{M} \varphi_{N 2 d} & \cdots & 1+P_{M} \varphi_{N N c}+D_{M} \varphi_{N N d}
\end{array}\right], \\
\mathbf{C}=\left[\begin{array}{cccc}
2 P_{M} \dot{x}_{c} \varphi_{11 c 1}+4 \xi_{1} \omega_{1}+C_{d} \varphi_{11 d} & 2 P_{M} \dot{x}_{c} \varphi_{12 c 1}+C_{d} \varphi_{12 d} & \cdots & 2 P_{M} \dot{x}_{c} \varphi_{1 N c 1}+C_{d} \varphi_{1 N d} \\
2 P_{M} \dot{x}_{c} \varphi_{21 c 1}+C_{d} \varphi_{21 d} & 2 P_{M} \dot{x}_{c} \varphi_{22 c 1}+4 \xi_{2} \omega_{2}+C_{d} \varphi_{22 d} & \cdots & 2 P_{M} \dot{x}_{c} \varphi_{2 N c 1}+C_{d} \varphi_{2 N d} \\
\vdots & \vdots & \ddots & \vdots \\
2 P_{M} \dot{x}_{c} \varphi_{N 1 c 1}+C_{d} \varphi_{N 1 d} & 2 P_{M} \dot{x}_{c} \varphi_{N 2 c 1}+C_{d} \varphi_{N 2 d} & \cdots & 2 P_{M} \dot{x}_{c} \varphi_{N N c 1}+4 \xi_{N} \omega_{N}+C_{d} \varphi_{N N d}
\end{array}\right],
\end{gathered}
$$

$\mathbf{K}$

$$
=\left[\begin{array}{cccc}
P_{M} \ddot{x}_{c} \varphi_{11 c 1}+P_{M} \dot{x}_{c}{ }^{2} \varphi_{11 c 2}+K_{d} \varphi_{11 d}+\frac{E I_{y} \pi^{4}}{m_{b} l_{b}{ }^{4}} & P_{M} \ddot{x}_{c} \varphi_{12 c 1}+P_{M} \dot{x}_{c}{ }^{2} \varphi_{12 c 2}+K_{d} \varphi_{12 d} & \cdots & P_{M} \ddot{x}_{c} \varphi_{1 N c 1}+P_{M} \dot{x}_{c}{ }^{2} \varphi_{1 N c 2}+K_{d} \varphi_{1 N d} \\
P_{M} \ddot{x}_{c} \varphi_{21 c 1}+P_{M} \dot{x}_{c}{ }^{2} \varphi_{21 c 2}+K_{d} \varphi_{21 d} & P_{M} \ddot{x}_{c} \varphi_{22 c 1}+P_{M} \dot{x}_{c}{ }^{2} \varphi_{22 c 2}+K_{d} \varphi_{22 d}+\frac{E I_{y} \pi^{4} 2^{4}}{m_{b} l_{b}{ }^{4}} & \cdots & P_{M} \ddot{x}_{c} \varphi_{2 N c 1}+P_{M} \dot{x}_{c}{ }^{2} \varphi_{2 N c 2}+K_{d} \varphi_{2 N d} \\
\vdots & \vdots & \ddots & \vdots \\
P_{M} \ddot{x}_{c} \varphi_{N 1 c 1}+P_{M} \dot{x}_{c}{ }^{2} \varphi_{N 1 c 2}+K_{d} \varphi_{N 1 d} & P_{M} \ddot{x}_{c} \varphi_{N 2 c 1}+P_{M} \dot{x}_{c}{ }^{2} \varphi_{N 2 c 2}+K_{d} \varphi_{N 2 d} & \cdots & P_{M} \ddot{x}_{c} \varphi_{N N c 1}+P_{M} \dot{x}_{c}{ }^{2} \varphi_{N N c 2}+K_{d} \varphi_{N N d}+\frac{E I_{y} \pi^{4} N^{4}}{m_{b} l_{b}{ }^{4}}
\end{array}\right],
$$




$$
\mathbf{F}(t)=\left(\begin{array}{c}
\phi_{1}\left(x_{c}\right)\left(P_{M} g+R_{M}\left(\ddot{\theta}_{x} \sin \theta_{x}+\dot{\theta}_{x}{ }^{2} \cos \theta_{x}\right)\right)+\phi_{1}\left(x_{d}\right)\left(D_{M} \ddot{z}_{d}+K_{d} z_{d}+C_{d} \dot{z}_{d}\right) \\
\phi_{2}\left(x_{c}\right)\left(P_{M} g+R_{M}\left(\ddot{\theta}_{x} \sin \theta_{x}+\dot{\theta}_{x}{ }^{2} \cos \theta_{x}\right)\right)+\phi_{2}\left(x_{d}\right)\left(D_{M} \ddot{z}_{d}+K_{d} z_{d}+C_{d} \dot{z}_{d}\right) \\
\vdots \\
\phi_{N}\left(x_{c}\right)\left(P_{M} g+R_{M}\left(\ddot{\theta}_{x} \sin \theta_{x}+\dot{\theta}_{x}{ }^{2} \cos \theta_{x}\right)\right)+\phi_{N}\left(x_{d}\right)\left(D_{M} \ddot{z}_{d}+K_{d} z_{d}+C_{d} \dot{z}_{d}\right)
\end{array}\right) .
$$

In these matrices: $P_{M}=2\left(m_{c}+m_{p}\right) / m_{b} l_{b} ; D_{M}=2 m_{d} / m_{b} l_{b}$; $R_{M}=\left(2 m_{p} \cdot l_{p}\right) / m_{b} l_{b} ; \varphi_{m n c 1}=\phi_{m}\left(x_{c}\right) \phi_{n}^{\prime}\left(x_{c}\right) ; \varphi_{m n c 2}=$ $\phi_{m}\left(x_{c}\right) \phi_{n}^{\prime \prime}\left(x_{c}\right) K_{d}=2 k_{d} / m_{b} l_{b} ; C_{d}=2 c_{d} / m_{b} l_{b} ; \varphi_{m n c}=$ $\phi_{m}\left(x_{c}\right) \phi_{n}\left(x_{c}\right) ; \varphi_{m n d}=\phi_{m}\left(x_{d}\right) \phi_{n}\left(x_{d}\right)$.

\section{Conflicts of Interest}

All the authors do not have any possible conflicts of interest.

\section{Acknowledgments}

This paper is sponsored by the Fund for Shanxi "1331Project" Key Subjects Construction and Postgraduate Innovation Project in Shanxi Province (2017BY118). The data of this work is provided by Taiyuan Heavy Industry Co., Ltd.

\section{References}

[1] G. Michaltsos, D. Sophianopoulos, and A. N. Kounadis, "The effect of a moving mass and other parameters on the dynamic response of a simply supported beam," Journal of Sound and Vibration, vol. 191, no. 3, pp. 357-362, 1996.

[2] M. Şimşek, "Vibration analysis of a functionally graded beam under a moving mass by using different beam theories," Composite Structures, vol. 92, no. 4, pp. 904-917, 2010.

[3] K. Kiani, A. Nikkhoo, and B. Mehri, "Prediction capabilities of classical and shear deformable beam models excited by a moving mass," Journal of Sound and Vibration, vol. 320, no. 3, pp. 632-648, 2009.

[4] A. Nikkhoo, F. R. Rofooei, and M. R. Shadnam, "Dynamic behavior and modal control of beams under moving mass," Journal of Sound and Vibration, vol. 306, no. 3-5, pp. 712-724, 2007.

[5] E. Esmailzadeh and M. Ghorashi, "Vibration analysis of beams traversed by uniform partially distributed moving masses," Journal of Sound and Vibration, vol. 184, no. 1, pp. 9-17, 1995.

[6] H. P. Lee, "The dynamic response of a timoshenko beam subjected to a moving mass," Journal of Sound and Vibration, vol. 198, no. 2, pp. 249-256, 1996.

[7] P. Lou, G.-L. Dai, and Q.-Y. Zeng, "Finite-element analysis for a Timoshenko beam subjected to a moving mass," Proceedings of the Institution of Mechanical Engineers, Part C: Journal of Mechanical Engineering Science, vol. 220, no. 5, pp. 669-678, 2006.

[8] P. Lou, Z. Yu, and F. T. K. Au, "Rail-bridge coupling element of unequal lengths for analysing train-track-bridge interaction systems," Applied Mathematical Modelling: Simulation and Computation for Engineering and Environmental Systems, vol. 36, no. 4, pp. 1395-1414, 2012.

[9] Y. S. Cheng, F. T. K. Au, and Y. K. Cheung, "Vibration of railway bridges under a moving train by using bridge-track-vehicle element," Engineering Structures, vol. 23, no. 12, pp. 1597-1606, 2001.

[10] C. M. Niu, H. W. Zhang, and H. Ouyang, "A comprehensive dynamic model of electric overhead cranes and the lifting operations," ARCHIVE Proceedings of the Institution of Mechanical Engineers Part C Journal of Mechanical Engineering Science, vol. 203-210, pp. 1484-1503, 1989-1996.

[11] J.-J. Wu, "Finite element modelling and experimental modal testing of a three-dimensional framework," International Journal of Mechanical Sciences, vol. 46, no. 8, pp. 1245-1266, 2004.

[12] J.-J. Wu, "Finite element analysis and vibration testing of a threedimensional crane structure," Measurement, vol. 39, no. 8, pp. 740-749, 2006.

[13] J. J. Wu, A. R. Whittaker, and M. P. Cartmell, "Dynamic responses of structures to moving bodies using combined finite element and analytical methods," International Journal of Mechanical Sciences, vol. 43, no. 11, pp. 2555-2579, 2001.

[14] J.-J. Wu, "Transverse and longitudinal vibrations of a frame structure due to a moving trolley and the hoisted object using moving finite element," International Journal of Mechanical Sciences, vol. 50, no. 4, pp. 613-625, 2008.

[15] D. C. D. Oguamanam, J. S. Hansen, and G. R. Heppler, "Dynamic response of an overhead crane system," Journal of Sound and Vibration, vol. 213, no. 5, pp. 889-906, 1998.

[16] D. C. D. Oguamanam, J. S. Hansen, and G. R. Heppler, "Dynamics of a three-dimensional overhead crane system," Journal of Sound and Vibration, vol. 242, no. 3, pp. 411-426, 2001.

[17] N. D. Zrnić, V. M. Gašić, and S. M. Bošnjak, "Dynamic responses of a gantry crane system due to a moving body considered as moving oscillator," Archives of Civil and Mechanical Engineering, vol. 15, no. 1, pp. 243-250, 2015.

[18] Y. Xin, G. Xu, and N. Su, "Dynamic optimization design of cranes based on human-crane-rail system dynamics and annoyance rate," Shock and Vibration, vol. 1, Article ID 8376058, pp. $1-19,2017$.

[19] Q. Dong, G. N. Xu, and H. L. Ren, "Research on risk of remanufacturing telescopic job structure system under potential multifailure mode correlation," Journal of Advanced Mechanical Design, Systems, and Manufacturing, vol. 11, no. 2, pp. 1-18, 2017.

[20] Q. Dong, G. N. Xu, H. L. Ren, and A. H. Wang, "Fatigue remaining life estimation for remanufacturing truck crane Jib structure based on random load spectrum," Fatigue \& Fracture of Engineering Materials \& Structures, vol. 40, no. 5, pp. 706-731, 2017.

[21] G. T. Michaltsos, "Dynamic behaviour of a single-span beam subjected to loads moving with variable speeds," Journal of Sound and Vibration, vol. 258, no. 2, pp. 359-372, 2002.

[22] Z. Jun and C. Zhi-jian, "The research about horizontal moving rule of bridge crane and swing rule of grab," Journal of Shandong University (Natural Science Edition), vol. 33, no. 4, pp. 393-397, 1998. 
[23] G. Xu, X. Fan, F. Lu, and H. Yang, "Monte Carlo simulation of fatigue reliabilities and initial cracks for welded box girders of crane," Journal of Mechanical Engineering, vol. 47, no. 20, pp. 4144, 2011.

[24] G. Xu and H. Li, "General bridge crane structure CAD based on working stress method and limit state design method," Hoisting and Conveying Machinery, vol. 10, pp. 72-78, 2008 (Chinese).

[25] B. Zheng, X. Gao, and C. Zhang, "Radial integration BEM for vibration analysis of two- and three-dimensional elasticity structures," Applied Mathematics and Computation, vol. 277, pp. 111-126, 2016.

[26] T. C. Chen, C. Su, Z. Q. Hu, and H. T. Ma, "An explicit timedomain method in sensitivity analysis of non-stationary random responses," Journal of Vibration Engineering, vol. 28, no. 4, pp. 503-509, 2015 (Chinese).

[27] Z. Hu, C. Su, T. Chen, and H. Ma, "An explicit time-domain approach for sensitivity analysis of non-stationary random vibration problems," Journal of Sound and Vibration, vol. 382, pp. 122-139, 2016. 


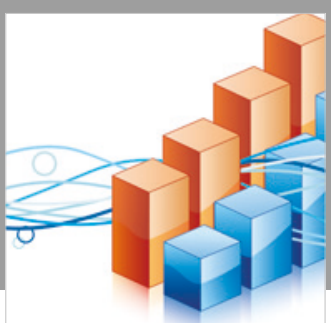

Advances in

Operations Research

\section{-n-m}
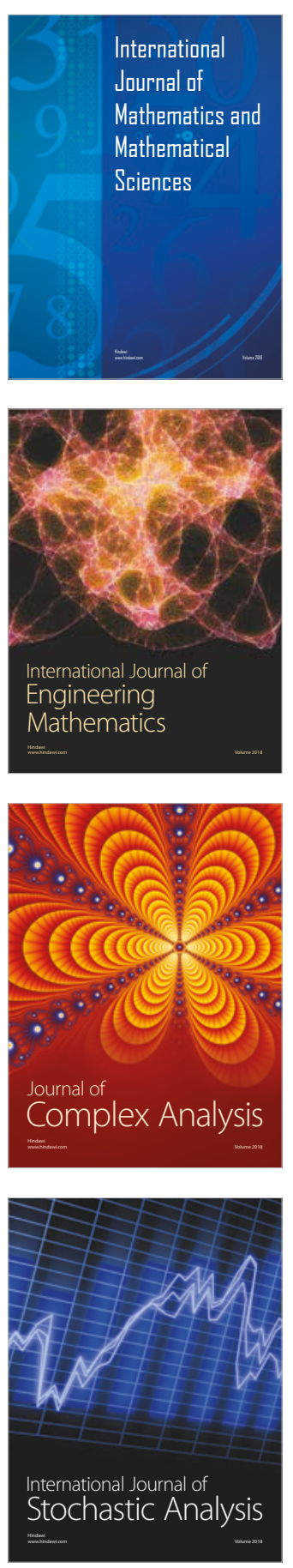
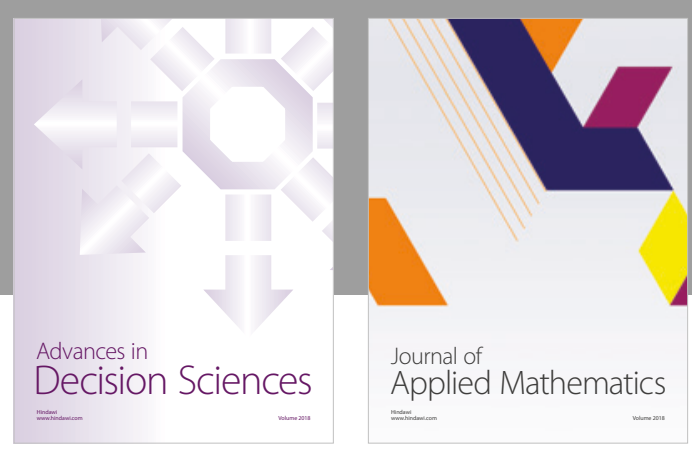

Journal of

Applied Mathematics
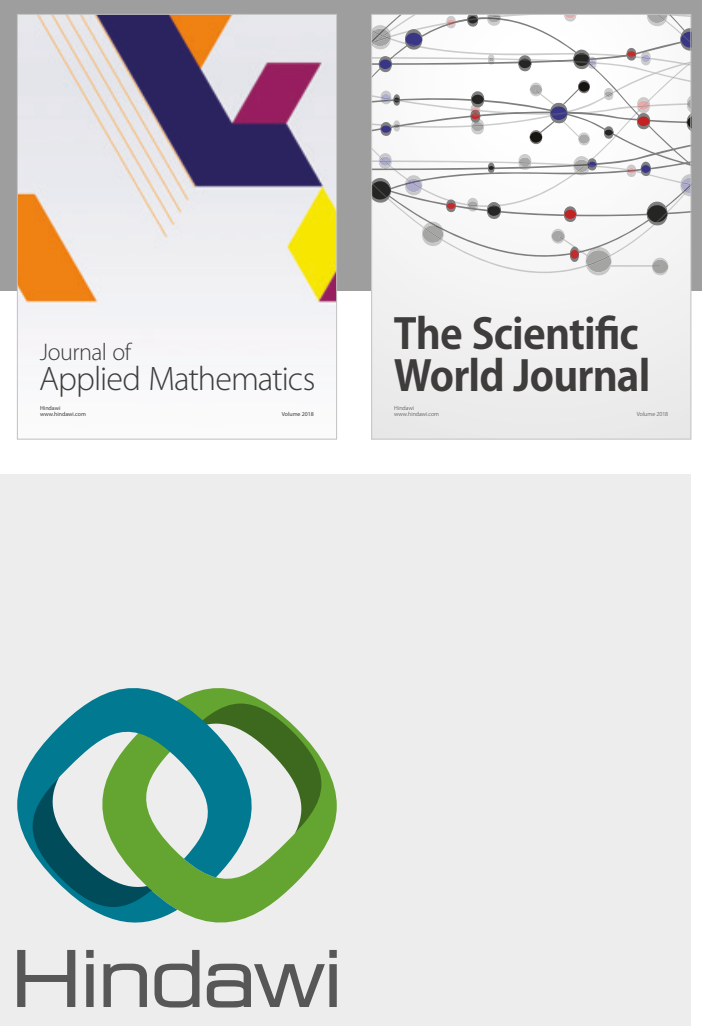

Submit your manuscripts at

www.hindawi.com

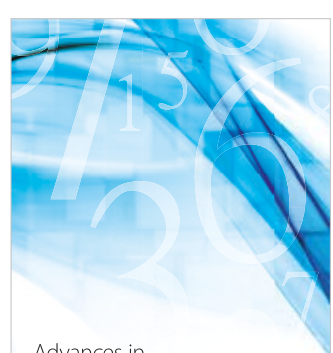

Advances in
Numerical Analysis
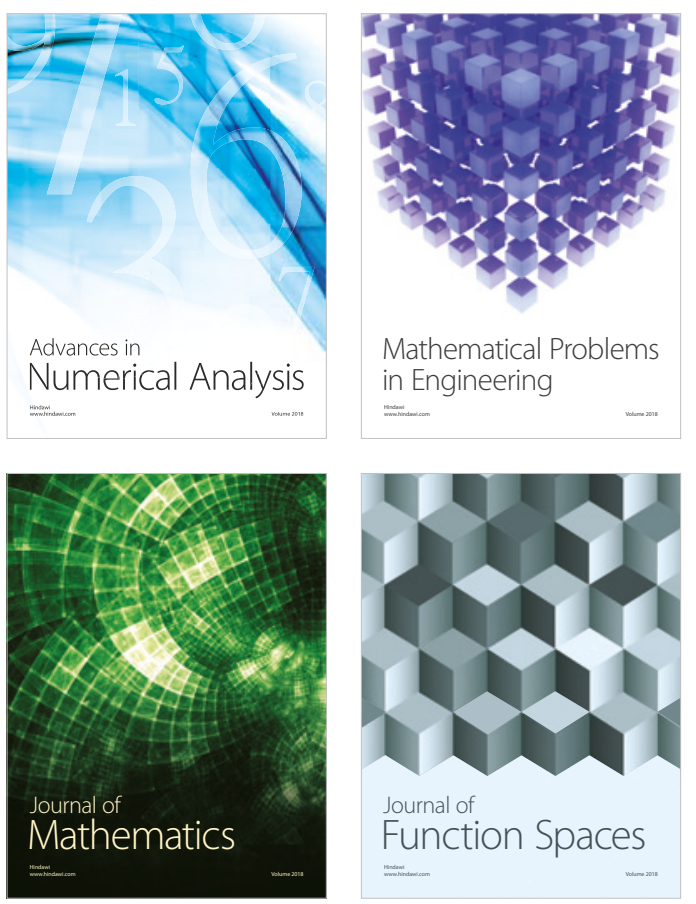

Mathematical Problems in Engineering

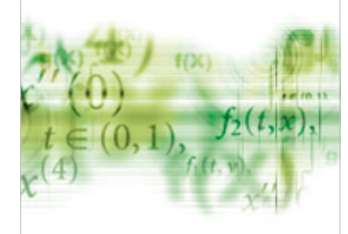

International Journal of

Differential Equations

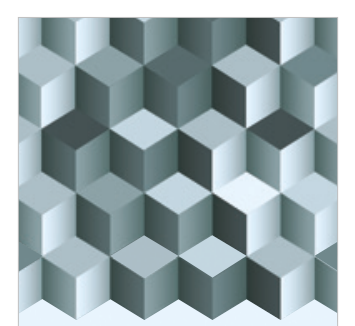

Journal of

Function Spaces

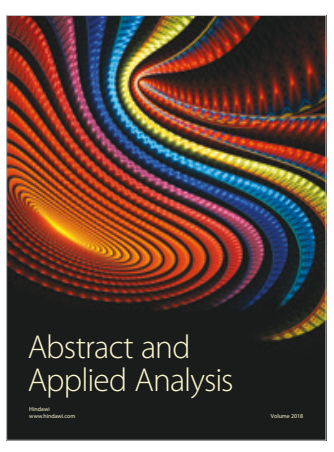

The Scientific

World Journal

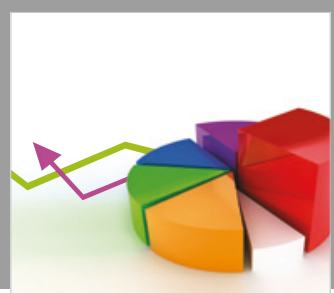

Journal of

Probability and Statistics
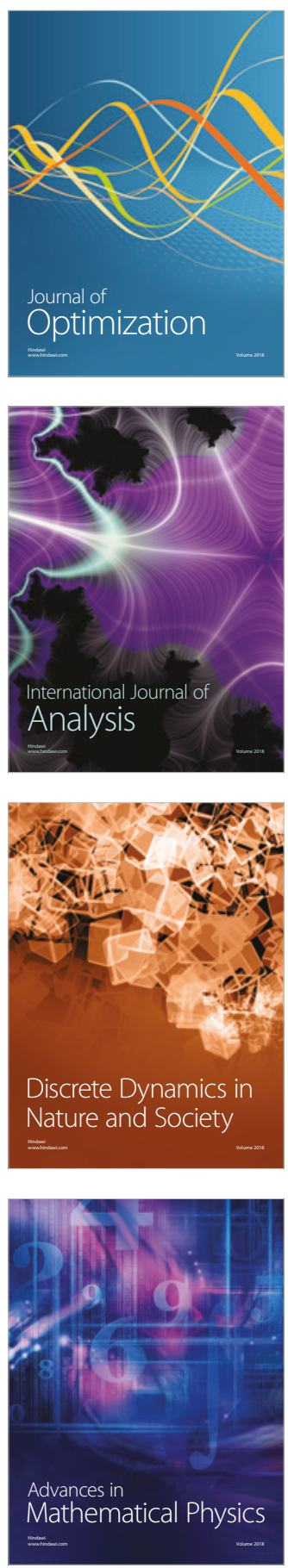